\title{
Mesoscale Air-Sea Interaction and Its Role in Eddy Energy Dissipation in the Kuroshio Extension
}

\author{
HAIYUAN YANG \\ Physical Oceanography Laboratory/Institute for Advanced Ocean Study, Ocean University of China, and Pilot National \\ Laboratory for Marine Science and Technology, Qingdao, China \\ PING CHANG \\ Physical Oceanography Laboratory/Institute for Advanced Ocean Study, Ocean University of China, and Pilot National \\ Laboratory for Marine Science and Technology, Qingdao, China, and Department of Oceanography, and Department of \\ Atmospheric Sciences, Texas A\&M University, College Station, Texas \\ Bo QIU \\ Physical Oceanography Laboratory/Institute for Advanced Ocean Study, Ocean University of China, and Pilot National \\ Laboratory for Marine Science and Technology, Qingdao, China, and Department of Oceanography, \\ University of Hawai'i at Mānoa, Honolulu, Hawaii \\ QIUYING ZHANG \\ Department of Oceanography, and Department of Atmospheric Sciences, Texas A\&M University, College Station, Texas

\section{LIXIN WU, ZHAOHUI CHEN, AND HONG WANG} \\ Physical Oceanography Laboratory/Institute for Advanced Ocean Study, Ocean University of China, and Pilot National \\ Laboratory for Marine Science and Technology, Qingdao, China
}

(Manuscript received 25 February 2019, in final form 15 August 2019)

\begin{abstract}
Using the high-resolution Community Earth System Model (CESM) output, this study investigates air-sea interaction and its role in eddy energy dissipation in the Kuroshio Extension (KE) region. Based on an eddy energetics analysis, it is found that the baroclinic pathway associated with temperature variability is the main eddy energy source in this region. Both the air-sea heat flux and wind stress act as eddy killers that remove energy from oceanic eddies. Heat exchange between atmosphere and oceanic eddies dominates the dissipation of eddy temperature variance within the surface layer and accounts for $36 \%$ of the total dissipation in the upper 350-m layer. Compared to the heat exchange, the role of wind power in damping the eddy kinetic energy (EKE) is relatively small. Only $18 \%$ of EKE dissipation in the upper $350 \mathrm{~m}$ is attributed to eddy wind power. Misrepresentation of the damping role of mesoscale ocean-atmosphere interaction can result in an incorrect vertical structure of eddy energy dissipation, leading to an erroneous representation of vertical mixing in the interior ocean.
\end{abstract}

\section{Introduction}

After separating from the Japanese coast, the Kuroshio flows into the open North Pacific Ocean and is renamed the Kuroshio Extension (KE). Without the constraint of coastal boundaries, the KE is found to be accompanied by large-amplitude meanders and energetic pinched-off eddies (e.g., Qiu et al. 1991; Joyce

Corresponding author: Haiyuan Yang, yanghaiyuan@ouc.edu.cn et al. 2001; Nakano et al. 2013; Kida et al. 2015; Sasaki and Minobe 2015; Fig. 1). Recent studies based on potential vorticity (PV) and energetics analysis demonstrated that eddies are mainly generated in the upstream $\mathrm{KE}$ through both baroclinic (BC) and barotropic (BT) instability, and dissipated in the downstream (Berloff and McWilliams 1999; Waterman and Jayne 2011; H. Yang et al. 2018). Regulated by the westwardpropagating baroclinic long Rossby waves and the jet stability, the eddy activity in the KE region exhibits 


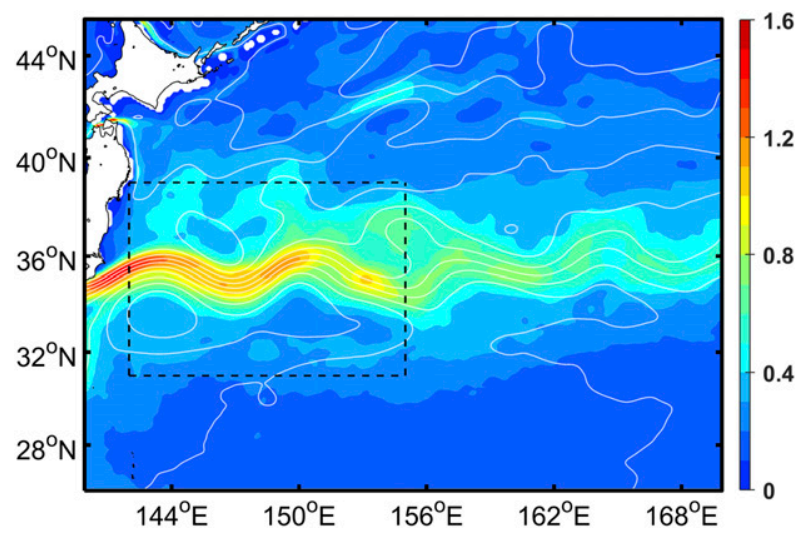

FIG. 1. Mean velocity field (color shading; $\mathrm{m} \mathrm{s}^{-1}$ ) based on the Community Earth System Model (CESM) in the western North Pacific. Contours denote mean sea surface height (SSH) field and the black box indicates the domain for eddy energetic analysis.

well-defined low-frequency modulations between a highEKE (eddy kinetic energy) and a low-EKE state (Qiu and Chen 2005, 2010; Taguchi et al. 2007; Yang et al. 2017; H. Yang et al. 2018). To date, eddy activity and its variability in the KE region have been emphasized by several studies to be important for the basin-scale ocean circulation and marine ecosystems in the North Pacific (Qiu and Chen 2011; Bishop 2013; Kida et al. 2015).

The KE is not only a region abundant with oceanic mesoscale variability, but also an area of intense air-sea interaction in the extratropics. The warm water from the tropics is rapidly transported northward by the Kuroshio into a region of much colder air, particularly in boreal winter, resulting in large loss of heat to the atmosphere. The heating effect of the KE on the overlying atmosphere mainly occurs in the upstream and reaches more than $600 \mathrm{~W} \mathrm{~m}^{-2}$ during winter (Konda et al. 2010; Kelly et al. 2010). This heat exchange regulates the instability of overlying air and plays an important role in the formation of storm tracks (Nakamura et al. 2004; Sampe and Xie 2007; Booth et al. 2010). In addition to the thermal feedback, the strong ocean currents can also affect the wind stress (Cornillon and Park 2001; Kelly et al. 2001) because wind stress depends on the relative motion of the atmosphere and the ocean. At decadal time scales, the KE jet, wind stress, and storm tracks form a coupled system: evolution of the KE influences the storm tracks and surface wind stress curl field across the North Pacific basin, while wind-induced westward-propagating baroclinic Rossby waves regulate the KE in return (Qiu et al. 2014).

Besides its large-scale influence, local mesoscale airsea interaction has an obvious impact on mesoscale eddies as well. Based on satellite observations, Chelton et al. (2004) found a quasi-linear relationship between wind stress curl and crosswind component of local sea surface temperature (SST) gradient, indicative of a dynamical coupling between eddies and atmosphere. Using an eddy-centric framework, Gaube et al. (2015) highlighted the importance of eddy current feedback. Current-induced surface wind stress curl change over an eddy can generate an Ekman pumping velocity that is of the opposite sign to the surface vorticity of the eddy (Eden and Dietze 2009; Gaube et al. 2015; Seo et al. 2016). Recently Renault et al. (2016a) summarized the current feedback mechanism. On one hand, eddyinduced wind stress anomalies produce a stress curl opposite to the eddy vorticity, dampening eddies and transferring EKE to the atmosphere. On the other hand, changes in atmospheric surface friction associated with the eddy-induced wind stress anomalies produce wind anomalies that oppose the anomalous stress curl, acting to reduce its damping effect on eddies. This eddy current feedback effect is supported by recent wind power analyses in the KE region (Xu et al. 2016; Yang and Liang 2018). In addition to EKE, recent high-resolution satellite observations and coupled atmosphere-ocean model simulations indicate a large potential energy release from mesoscale ocean fronts and eddies to the overlying atmosphere in the North Pacific Ocean (Bishop et al. 2015; Ma et al. 2016; Bishop et al. 2017). Their eddy energy budget analyses show that eddy potential energy (EPE) can be dissipated directly through strong mesoscale airsea interaction, whereas more EPE is fed into EKE when the mesoscale coupling is suppressed.

While these previous studies have significantly improved our knowledge on the role of air-sea interaction in regulating mesoscale eddies, many important issues remain unsolved. First, a detailed breakdown of air-sea interaction contribution to eddy energy balance has yet to be fully quantified. Second, and more importantly, the effect of air-sea interaction on the vertical structure of eddy energy dissipation remains largely unknown. These issues pose hindrances to our understanding of the basic eddy dynamics in the KE region. In this paper, the abovementioned issues are examined through analyzing an eddy-resolving coupled climate model simulation. The rest of this paper is organized as follows: section 2 gives a brief description of the datasets and method used in this study. In section 3, a detailed study of air-sea interaction and its role in energy dissipation is presented. The paper ends with a summary and further discussion in section 4 .

\section{Data and method}

\section{a. Method}

In this study, eddy energetics in the KE region is analyzed using a multiscale energy and vorticity analysis method (MS-EVA; Liang and Robinson 2005; 
Liang 2016). Based on wavelet analyses (Meyer wavelet is used in this study), MS-EVA decomposes time series into several time-scale windows orthogonally without changing the total energy. Here, we decompose the variables into three windows:

$$
A=A^{\sim 0}+A^{\sim 1}+A^{\sim 2},
$$

where $\sim 0, \sim 1$, and $\sim 2$ represent mean flow, mesoscale eddies, and high-frequency processes, respectively. Here, high-frequency processes include ocean response to synoptic-scale atmospheric processes and submesoscale eddies, Ekman drift, and turbulence in the ocean. A two-window decomposition is typically employed in previous studies to examine ocean eddy energetics (e.g., von Storch et al. 2012; Yang et al. 2017). However, it is found that the eddy wind work for periods shorter than $\sim 2$ weeks is positive rather than negative, suggesting that the high-frequency eddy wind work is forcing rather than damping EKE as shown by many previous studies (Gaube et al. 2015; Renault et al. 2016a, 2017; Xu et al. 2016; Yang and Liang 2018). Upon further examination, we find that at the high-frequency band (weekly time scales), the ocean variability is dominated by atmospheric synoptic storms forcing the ocean in the KE region (see more discussion in section 3). Therefore, we design the three-frequency wavelet filter to separate the low frequency, the oceanic mesoscale frequency, and the atmospheric synoptic frequency variability in this

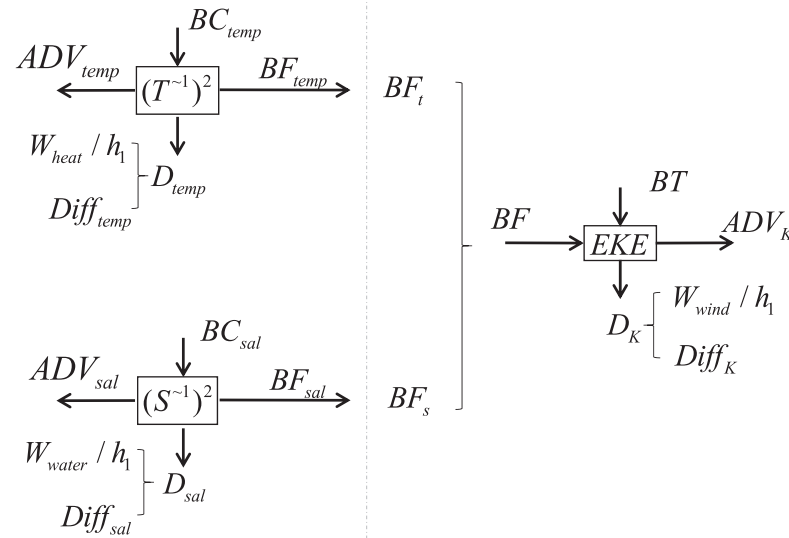

FIG. 2. Schematic of the eddy energy budget.

study. According to previous estimations, the cutoff period is set at 270 days between mean flow and mesoscale eddies (Itoh and Yasuda 2010; Yang et al. 2017) and 17 days (Gan and $\mathrm{Wu} 2015$ ) between mesoscale eddies and high-frequency processes, respectively. Changing these cutoff periods from 210 days (13 days) to 330 days ( 21 days) generates no significant difference in the results. The energy equations within the mesoscale window are (Fig. 2) the following:

$$
\begin{aligned}
& \rho_{0} \frac{\partial}{\partial t} \mathrm{EKE}=\frac{\partial}{\partial t} \rho_{0} \frac{\left(u^{\sim 1}\right)^{2}+\left(v^{\sim 1}\right)^{2}}{2}= \underbrace{-\rho^{\sim 1} w^{\sim 1} g}_{\mathrm{BF}} \underbrace{+\frac{1}{2} \rho_{0}\left\{\left(\mathbf{v v}_{H}\right)^{\sim 1}: \nabla \mathbf{v}_{H}^{\sim 1}-\left[\nabla \cdot\left(\mathbf{v v}_{H}\right)^{\sim 1}\right] \cdot \mathbf{v}_{H}^{\sim 1}\right\}}_{\mathrm{BT}} \\
& \underbrace{-\nabla \cdot\left[\frac{1}{2} \rho_{0}\left(\mathbf{v v}_{H}\right)^{\sim 1} \cdot \mathbf{v}_{H}^{\sim 1}+p^{\sim 1} \mathbf{v}^{\sim 1}\right]}_{\mathrm{ADV}_{K}} \underbrace{+\rho_{0} \mathbf{v}_{H}^{\sim 1} \cdot\left(A_{M} \nabla^{2} \mathbf{v}_{H}+\frac{\partial}{\partial z} \mu \frac{\partial \mathbf{v}_{H}}{\partial z}\right)^{\sim 1}}_{D_{K}},
\end{aligned}
$$

$$
\begin{aligned}
\frac{\partial}{\partial t} \frac{\left(T^{\sim 1}\right)^{2}}{2}= & \underbrace{\frac{1}{2}\left\{(\mathbf{v} T)^{\sim 1} \cdot \nabla T^{\sim 1}-\left[\nabla \cdot(\mathbf{v} T)^{\sim 1}\right] \cdot T^{\sim 1}\right\}}_{\mathrm{BC}_{\text {temp }}} \underbrace{-T^{\sim 1} w^{\sim 1} \frac{\partial \bar{T}(z)}{\partial z}}_{\mathrm{BF}_{\text {temp }}} \underbrace{-\nabla \cdot\left[\frac{T^{\sim 1}}{2}(T \mathbf{v})^{\sim 1}\right]}_{\mathrm{ADV}_{\text {temp }}} \\
& \underbrace{+T^{\sim 1} \cdot\left\{A_{H} \nabla^{2} T+\frac{\partial}{\partial z} \kappa \frac{\partial[T+\bar{T}(z)]}{\partial z}+F_{T}\right\}^{\sim 1}}_{D_{\text {temp }}},
\end{aligned}
$$




$$
\begin{aligned}
\frac{\partial}{\partial t} \frac{\left(S^{\sim 1}\right)^{2}}{2}= & \underbrace{\frac{1}{2}\left\{(\mathbf{v} S)^{\sim 1} \cdot \nabla S^{\sim 1}-\left[\nabla \cdot(\mathbf{v} S)^{\sim 1}\right] \cdot S^{\sim 1}\right\}}_{\mathrm{BC}_{\text {sal }}} \underbrace{-S^{\sim 1} w^{\sim 1} \frac{\partial \bar{S}(z)}{\partial z}}_{\mathrm{BF}_{\text {sal }}} \underbrace{-\nabla \cdot\left[\frac{S^{\sim 1}}{2}(S \mathbf{v})^{\sim 1}\right]}_{\mathrm{ADV}_{\text {sal }}} \\
& \underbrace{+S^{\sim 1} \cdot\left\{A_{H} \nabla^{2} S+\frac{\partial}{\partial z} \kappa \frac{\partial[S+\bar{S}(z)]}{\partial z}+F_{S}\right\}^{\sim 1}}_{D_{\text {sal }}} \cdot
\end{aligned}
$$

Here $\mathbf{v}=(u, v, w)$ and $\mathbf{v}_{H}=(u, v)$ represent the full and horizontal velocity vectors, respectively; $T$ is the potential temperature perturbation from the background profile $\bar{T}(z)$, and $S$ denotes the salinity anomaly from $\bar{S}(z)$. Also, $F_{T} / F_{S}$ represents the nonlocal $T / S$ transport due to the entrainment process parameterized using the $K$-profile parameterization (KPP) mixing scheme (Large et al. 1994); $\rho$ is the density with reference value $\rho_{0}$ and $p$ indicates pressure. The terms $A_{H}$ and $A_{M}$ are the coefficients (assumed to be spatially constant in the model) for horizontal eddy diffusion and viscosity, respectively; $\kappa$ and $\mu$ are the corresponding vertical mixing coefficients, which depend on the local state and mixing parameterization. The operator $\nabla$ represents the three-dimensional gradient operator and symbol ":" is defined as $(\mathbf{A B}):(\mathbf{C D})=(\mathbf{A} \cdot \mathbf{B})(\mathbf{C} \cdot \mathbf{D})$. Detailed derivations of Eq. (2) are given in appendix A. In Eq. (2a), $-\rho^{\sim 1} w^{\sim 1} g$, the first term on the right-hand side, describes conversion of EPE to EKE through buoyancy forcing (BF). The second term $1 / 2 \rho_{0}\left\{\left(\mathbf{v v}_{H}\right)^{\sim 1}: \nabla \mathbf{v}_{H}^{\sim 1}-\left[\nabla \cdot\left(\mathbf{v v}_{H}\right)^{\sim 1}\right] \cdot \mathbf{v}_{H}^{\sim 1}\right\}$ denotes the energy transfer between mean flow and eddy through BT. Once generated, EKE is transported out of the domain by nonlocal processes of energy flux divergence $\mathrm{ADV}_{K}$ through advection and pressure work, or balanced by energy dissipation $D_{K}$. Here, $D_{K}$ can be further divided into surface forcing $\left(W_{\text {wind }}\right)$ and oceanic mixing components $\left(\operatorname{Diff}_{K}\right)$ :

$$
\begin{aligned}
D_{K} & =\rho_{0} \mathbf{v}_{H}^{\sim 1} \cdot\left(A_{M} \nabla^{2} \mathbf{v}_{H}+\left.\frac{\partial}{\partial z} \mu \frac{\partial \mathbf{v}_{H}}{\partial z}\right|_{\text {ocean }}\right)^{\sim 1}+\rho_{0} \mathbf{v}_{H}^{\sim 1} \cdot\left(\left.\frac{\partial}{\partial z} \mu \frac{\partial \mathbf{v}_{H}}{\partial z}\right|_{\text {surface }}\right)^{\sim 1} \\
& =\rho_{0} \mathbf{v}_{H}^{\sim 1} \cdot\left(A_{M} \nabla^{2} \mathbf{v}_{H}+\left.\frac{\partial}{\partial z} \mu \frac{\partial \mathbf{v}_{H}}{\partial z}\right|_{\text {ocean }}\right)^{\sim 1}+\left.\rho_{0} \mathbf{v}_{H}^{\sim 1}\right|_{\text {surface }} \cdot \frac{\tau^{\sim 1}}{\rho_{0} h_{1}} \\
& =\operatorname{Diff}_{K}+\frac{W_{\text {wind }}}{h_{1}}
\end{aligned}
$$

where $h_{1}$ represents the depth of the first level $(10 \mathrm{~m}$ in CESM), $\mathbf{v}_{\text {surface }}$ is the surface horizontal velocity, and $\tau$ represents the surface wind stress. Physically, $W_{\text {wind }}$ describes wind power input whereas Diff $_{K}$ involves the oceanic friction and bottom drag processes. Equations (2b) and (2c), respectively, describe the sources and sinks for temperature ( $T$-variance) and salinity variance ( $S$-variance), which are closely related to EPE. Different from previous studies (Chen et al. 2014; Yang et al. 2017; Yang and Liang 2018), the classic EPE equation based on density field (Lorenz 1955) is not used here. This is because in the classic equation, energy terms are divided by buoyancy frequency $\left(N^{2}\right)$, which is very small near the sea surface, and can lead to an extremely surface-intensified EPE vertical structure and large uncertainties in the estimation of the air-sea interaction (not shown). Furthermore, temperature and salinity are prognostically determined by the model with heat and freshwater fluxes as forcing, respectively, and the daily mean terms in these equations are saved as model output, while density is determined diagnostically via the equation of state. As such, eddy energetics analysis can be carried out more accurately by directly using $T$ - and $S$-variance equations rather than the density-based EPE equation. According to Eq. (2b), the change of $T$-variance is regulated by baroclinic conversion $\left(\mathrm{BC}_{\text {temp }}\right.$; energy transfer from mean potential energy to EPE associated with temperature variability), EPE-to-EKE conversion $\left(\mathrm{BF}_{\text {temp }}\right.$; energy transfer from EPE to EKE associated with temperature variability), advection effects $\left(\mathrm{ADV}_{\text {temp }}\right)$, and dissipation ( $\left.D_{\text {temp }}\right)$. Equation (2c) is the same as Eq. (2b) but for $S$-variance. Similar to $D_{K}, D_{\text {temp }}$ and $D_{\text {sal }}$ can also be decomposed into their surface forcing and oceanic diffusion components: 


$$
\begin{aligned}
D_{\text {temp }} & =T^{\sim 1} \cdot\left(A_{H} \nabla^{2} T^{\sim 1}+\left\{\left.\frac{\partial}{\partial z} \kappa \frac{\partial[T+\bar{T}(z)]}{\partial z}\right|_{\text {ocean }}\right\}^{\sim 1}+F_{T}^{\sim 1}\right)+T^{\sim 1} \cdot\left\{\left.\frac{\partial}{\partial z} \kappa \frac{\partial[T+\bar{T}(z)]}{\partial z}\right|_{\text {surface }}\right\}^{\sim 1} \\
& =T^{\sim 1} \cdot\left(A_{H} \nabla^{2} T^{\sim 1}+\left\{\left.\frac{\partial}{\partial z} \kappa \frac{\partial[T+\bar{T}(z)]}{\partial z}\right|_{\text {ocean }}\right\}^{\sim 1}+F_{T}^{\sim 1}\right)+\operatorname{SST}^{\sim 1} \times \frac{Q_{\text {net }}^{\sim 1}}{C_{p} \rho_{0} h_{1}} \\
& =\text { Diff }_{\text {temp }}+\frac{W_{\text {temp }}}{h_{1}}
\end{aligned}
$$

and

$$
\begin{aligned}
D_{\text {sal }} & =S^{\sim 1} \cdot\left(A_{H} \nabla^{2} S^{\sim 1}+\left\{\left.\frac{\partial}{\partial z} \kappa \frac{\partial[S+\bar{S}(z)]}{\partial z}\right|_{\text {ocean }}\right\}^{\sim 1}+F_{S}^{\sim 1}\right)+S^{\sim 1} \cdot\left\{\left.\frac{\partial}{\partial z} \kappa \frac{\partial[S+\bar{S}(z)]}{\partial z}\right|_{\text {surface }}\right\}^{\sim 1} \\
& =S^{\sim 1} \cdot\left(A_{H} \nabla^{2} S^{\sim 1}+\left\{\left.\frac{\partial}{\partial z} \kappa \frac{\partial[S+\bar{S}(z)]}{\partial z}\right|_{\text {ocean }}\right\}^{\sim 1}+F_{S}^{\sim 1}\right)+\mathrm{SSS}^{\sim 1} \cdot \frac{1}{\rho_{0} h_{1}}[-(E-P) \cdot \mathrm{SSS}]^{\sim 1} \\
& =\operatorname{Diff}_{\text {sal }}+\frac{W_{\text {sal }}}{h_{1}}
\end{aligned}
$$

respectively. Here $Q_{\text {net }}$ is the net surface heat flux, $C_{p}$ denotes the specific heat for seawater, $E / P$ indicates the evaporation/precipitation rate, and SSS is the sea surface salinity. In the equations, $W_{\text {heat }}\left(W_{\text {sal }}\right)$ represents dissipation at the air-sea interface due to heat (freshwater) exchange with the atmosphere, while Diff temp $_{\text {en }}$ $\left(\right.$ Diff $\left._{\text {sal }}\right)$ is mixing and diffusion processes within the ocean interior. It this study, the discussion of penetrative shortwave radiation is not included because its value is negligible in the mesoscale window. The $T$-variance and $S$-variance equations are connected to the EKE equation through the approximate equation of state in the ocean for CESM model (Smith et al. 2010):

$$
\rho^{\sim 1}=\alpha T^{\sim 1}+\beta S^{\sim 1},
$$

where the reference values for $\alpha$ and $\beta$ are -0.25 $\left(\mathrm{kg} \mathrm{m}^{-3}\right){ }^{\circ} \mathrm{C}^{-1}$ and $0.76\left(\mathrm{~kg} \mathrm{~m}^{-3}\right)\left(\mathrm{g} \mathrm{kg}^{-1}\right)^{-1}$, respectively. We have tested the robustness of this approximation and found that it works well in the upperlayer KE region (not shown). Based on Eq. (6), the BF term in Eq. (2a) can be decomposed into the temperatureinduced and salinity-induced components:

$$
\mathrm{BF}=\mathrm{BF}_{t}+\mathrm{BF}_{s}=-\alpha T^{\sim 1} w^{\sim 1} g-\beta S^{\sim 1} w^{\sim 1} g .
$$

By multiplying the vertical gradient of background temperature and salinity profiles

$$
\begin{aligned}
\mathrm{BF}_{\text {temp }} & =\mathrm{BF}_{t} \times \frac{\partial \bar{T}(z)}{\partial z} / \alpha g, \\
\mathrm{BF}_{\text {sal }} & =\mathrm{BF}_{s} \times \frac{\partial \bar{S}(z)}{\partial z} / \beta g,
\end{aligned}
$$

these two components are connected to $\mathrm{BF}_{\text {temp }}$ and $\mathrm{BF}_{\text {sal }}$, respectively.

\section{b. Data}

\section{1) CESM MODEL}

The high-resolution model simulation used in this study is based on a version of the Community Earth System Model (CESM) developed as a part of the Accelerated Scientific Discovery (ASD) initiative at the National Center for Atmospheric Research (NCAR). A detailed model description is provided by Small et al. (2014). Here we briefly describe its atmospheric component-the Community Atmosphere Model version5 (CAM5) and its oceanic component-the Parallel Ocean Program version 2 (POP2). CAM5 is based on a global cubed-sphere grid at horizontal resolution of about $0.25^{\circ}$ with 30 pressure levels in the vertical direction. POP2 is a finite-difference code on an Arakawa B grid (velocities are specified at tracer cell corners) with horizontal resolution of $0.1^{\circ}$ and $62 z$ levels in the vertical. It includes a KPP turbulent mixing closure scheme (Large et al. 1994) for vertical mixing and a biharmonic horizontal diffusion and viscosity. CESM consists of a comprehensive coupling software framework that allows frequent mass, momentum, and energy exchanges at the air-sea interface. In particular, POP2 provides SST and surface velocity to CAM5 while receiving momentum, heat, and "salt" fluxes from the CAM5 based on surface flux scheme developed by Large and Yeager (2009) at a coupling interval of every $6 \mathrm{~h}$ (Small et al. 2014). Small et al. (2014) presented the results of a 100-yr simulation of this high-resolution CESM, 
which includes a 14-yr spinup run. In this study, we extended this simulation for 4 more years and saved all the daily mean terms in Eq. (2) except for the local vertical mixing terms of temperature and salinity, so that a detailed eddy energy budget analysis can be performed. The results presented below are based on the analysis performed in the KE region $\left(25^{\circ}-45^{\circ} \mathrm{N}\right.$, $\left.140^{\circ}-170^{\circ} \mathrm{E}\right)$.

To make a consistent assessment on the role of mesoscale air-sea interaction in regulating ocean eddy energetics, we conduct an ocean-alone simulation within the framework of CESM where its ocean and sea ice component, POP2/CICE, are forced by a given atmospheric forcing field rather than by the atmospheric component in the coupled experiment. As such, the atmosphere cannot respond to SST changes and the atmospheric boundary layer feedback, which acts to reduce the air-sea difference (Barsugli and Battisti 1998; Renault et al. 2016a; P. Yang et al. 2018) is not permitted in this ocean-alone run. The initial condition of the simulation is based on climatology January-mean temperature and salinity from World Ocean Atlas 2013 version 2 data (WOA13v2; https://www.nodc.noaa.gov/ OC5/woa13/woa13data.html) and the model is driven by 6-hourly climatological sea surface wind, temperature, and pressure fields derived from the National Centers for Environmental Prediction (NCEP) reanalysis product during the period of 1958-2008 (https://www.esrl.noaa. gov/psd/data/gridded/data.ncep.reanalysis.surfaceflux. $\mathrm{html}$ ), daily climatological atmospheric radiation from NASA Goddard Institute for Space Studies (GISS; https://www.giss.nasa.gov/) for the period of 19842000 , and daily climatological precipitation from the GXGXS dataset (a blend of GPCP, Xie-Arkin, and Serreze data) for the period of 1979-2000 (Large and Yeager 2004). The model was run for 16 years and daily output for the last 4 years within the KE region $\left(25^{\circ}-45^{\circ} \mathrm{N}, 140^{\circ}-170^{\circ} \mathrm{E}\right)$ were used in this study. Although the forcing field used in this experiment is not the same as that in the coupled simulation, the ocean and sea ice models are identical. A comparison of the simulated mean circulation indicates that both the spatial distribution and strength of the mean current in the KE region are similar between the two simulations, despite the different forcing fields (appendix B), suggesting that the difference in the forcing field does not have a major impact on the mean circulation in the KE region. Therefore, we expect that the baroclinic eddy generation process in the two simulations is not significantly altered by the difference in the forcing field, which justifies a direct comparison of eddy energetics between the two cases.

\section{2) ECCO2 StAte estimate}

In addition to the comparison between CESM coupled and ocean-alone simulations, to further validate the CESM coupled simulation, the Estimating the Circulation and Climate of the Ocean (ECCO) Phase II product (ECCO2; http://apdrc.soest.hawaii.edu/data/; cube92 version) is used in this study. ECCO2 is based on the Massachusetts Institute of Technology General Circulation Model (MITgcm; Marshall et al. 1997). The model has a horizontal resolution of $0.25^{\circ}$ and 50 vertical levels. Similar to CSEM, the KPP vertical mixing scheme is employed to parameterize subgrid-scale vertical mixing processes and biharmonic friction is used in horizontal direction. The eddy-permitting ECCO2 product is obtained by the least squares fit of the MITgcm to available observations. Based on the Green's function approach method (Menemenlis et al. 2005), the least squares fit is applied for several control parameters: the initial condition of temperature and salinity, background vertical viscosity and diffusivity, surface boundary conditions, and bottom drag coefficient. With these optimized control parameters, the model is run forward freely without the direct insertion of observational data. Therefore, the ECCO2 state estimate is regarded to be both realistic and dynamically consistent (Wunsch et al. 2009). The ECCO2 state estimate has been used in previous studies to explore eddy dynamics in the KE region (e.g., Chen et al. 2014; Yang et al. 2017; H. Yang et al. 2018). Here, the 3-day-averaged dataset in the $\mathrm{KE}$ region $\left(25^{\circ}-45^{\circ} \mathrm{N}, 140^{\circ}-170^{\circ} \mathrm{E}\right)$ from 1993 to 2016 is used.

\section{Role of air-sea interaction in eddy energy balance}

\section{a. Eddy energy balance}

Before exploring the eddy dynamics, it is necessary to quantify whether CESM can accurately capture the eddy activity in the KE region. Figures $3 \mathrm{a}$ and $3 \mathrm{~b}$ compare the time-mean surface EKE fields derived from CESM and ECCO2. The EKE pattern derived from CESM resembles that from $\mathrm{ECCO} 2$, both of which are characterized by large values in the vicinity of $\mathrm{KE}$ jet with the largest amplitude located between the quasi-stationary meander and the second crest $\left(34^{\circ}-36^{\circ} \mathrm{N}, 146^{\circ}-150^{\circ} \mathrm{E}\right)$. It is noted that the magnitude of EKE derived from CESM is larger than that derived from $\mathrm{ECCO}$, which may be caused by the coarser resolution of ECCO2. To test this, a $0.3^{\circ} \times 0.3^{\circ}$ (9 points) and 3-day average are applied to the CESM velocity field. The resultant magnitudes of EKE are found to be more comparable to each other between CESM and ECCO2 (not shown). In addition to the horizontal consistency, a 

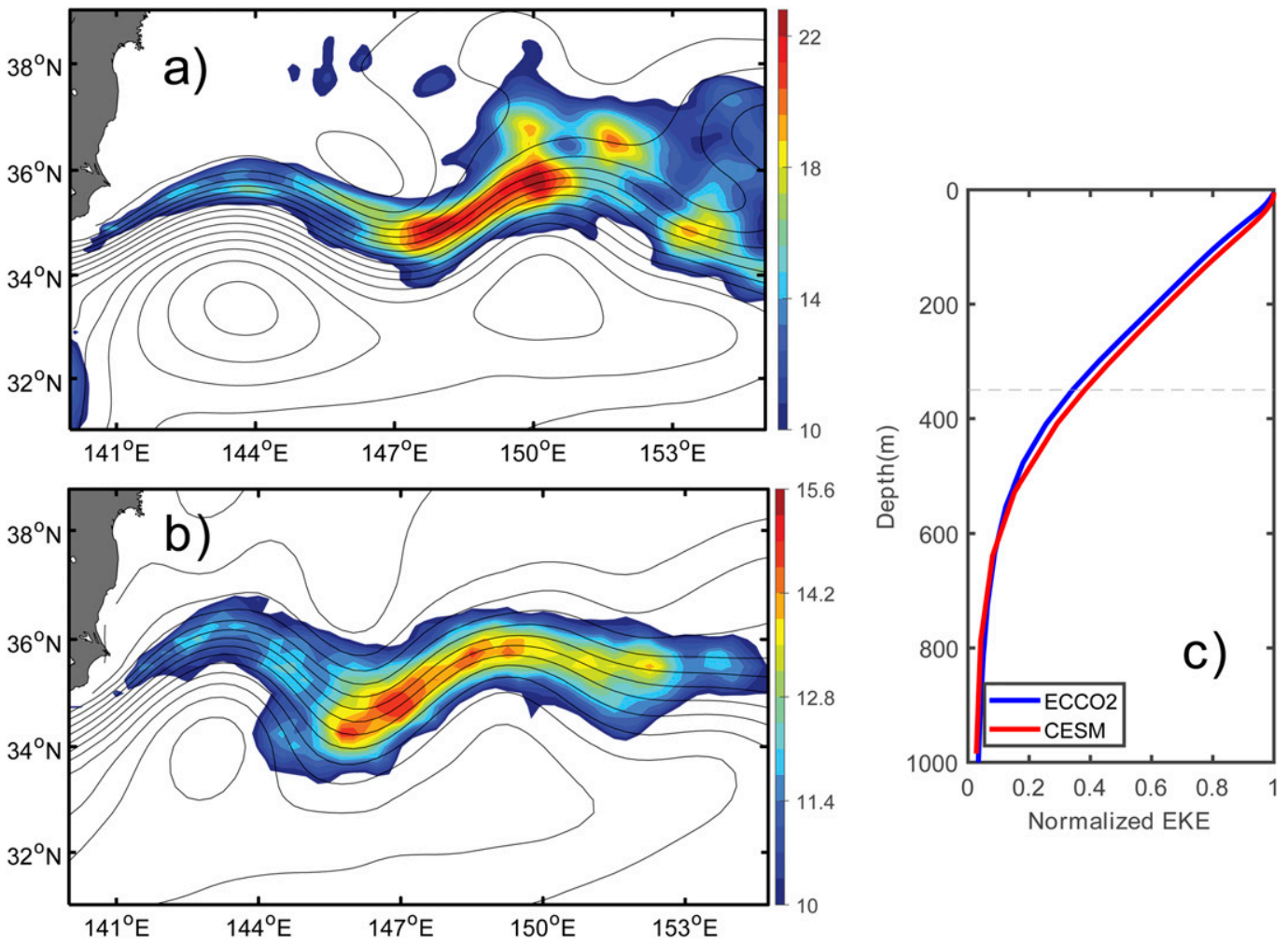

FIG. 3. Time-mean surface EKE field based on (a) CESM and (b) ECCO2 (color shading; $0.01 \mathrm{~m}^{2} \mathrm{~s}^{-2}$ ). Contours denote the mean SSH field. (c) Vertical structure of EKE from two datasets. Both curves are normalized by their surface values. Dashed line indicates $350 \mathrm{~m}$.

comparison between the two vertical distributions reveals that both EKE fields are dominated by a similar surfaceintensified structure with an $e$-folding scale about $350 \mathrm{~m}$ (Fig. 3c). Overall, this suggests that CESM realistically simulates the horizontal and vertical structures of the eddy activity in the KE region. In the following discussion, we will examine its eddy energy balance through budget analysis.

Figure 4 summarizes the budget for $\operatorname{EKE},\left(T^{\sim 1}\right)^{2}$ and $\left(S^{\sim 1}\right)^{2}$ in the upper 350-m layer in the KE region

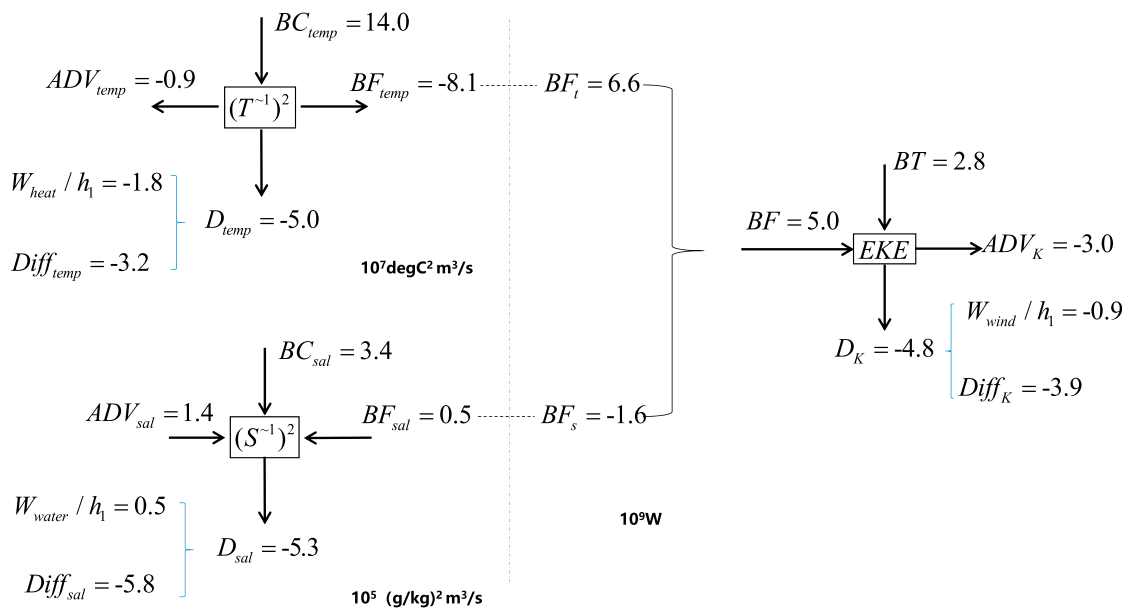

FIG. 4. Eddy energy budget for EKE, $\left(T^{1}\right)^{2}$, and $\left(S^{\sim 1}\right)^{2}$ in the upper $350 \mathrm{~m} \mathrm{KE}$ region $\left(31^{\circ}-39^{\circ} \mathrm{N}, 142^{\circ}-155^{\circ} \mathrm{E}\right)$ derived from CESM. 

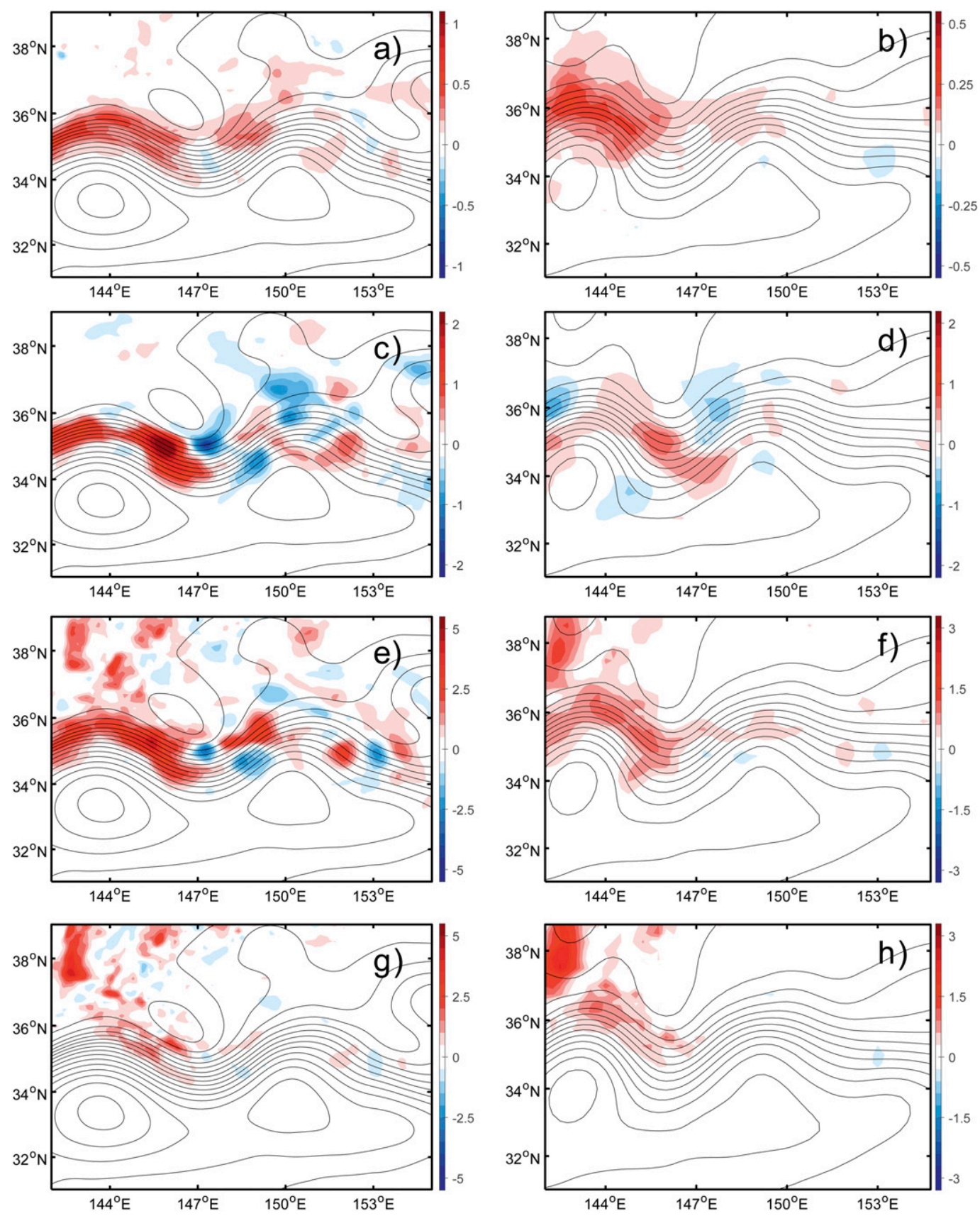

FIG. 5. Horizontal distribution of (a) BF (colored shading; $10^{-1} \mathrm{~W} \mathrm{~m}^{-2}$ ), (c) BT (colored shading; $10^{-1} \mathrm{~W} \mathrm{~m}^{-2}$ ), (e) $\mathrm{BC}_{\text {temp }}$ (color shading; $10^{-3}{ }^{\circ} \mathrm{C}^{2} \mathrm{~m} \mathrm{~s}^{-1}$ ), and (g) $\mathrm{BC}_{\text {sal }}$ [color shading; $10^{-5}\left(\mathrm{~g} \mathrm{~kg}^{-1}\right)^{2} \mathrm{~m} \mathrm{~s}^{-1}$ ] integrated over the upper $350 \mathrm{~m}$ derived from CESM. Contours are mean SSH isolines. (b),(d),(f),(h) As in (a),(c),(e),(g), but derived from ECCO2.

$\left(31^{\circ}-39^{\circ} \mathrm{N}, 142^{\circ}-155^{\circ} \mathrm{E}\right)$ derived from CESM. To get a better understanding of the dynamics, the horizontal distributions of energy production terms from both CESM and ECCO2 are also provided (Fig. 5). Figures $5 \mathrm{a}$ and $5 \mathrm{~b}$ show significant energy conversion from EPE to EKE along the KE jet with maximum occupying the first crest of meander. A negative spot is seen on the eastern side of the trough, which may be caused by the positive vertical velocity anomaly related to the recurring passages of cold rings in that area (Bishop 2013). In addition to the EPE-to-EKE conversion, eddies also draw their energy from the mean flow through BT (Figs. 5c,d), especially near the trough of the meandering $\mathrm{KE}$ jet $\left(35^{\circ} \mathrm{N}, 146^{\circ} \mathrm{E}\right)$. 
Compared to BF, BT exhibits a clear longitudinal variability: positive and negative values appear one after another along the KE jet axis. This phenomenon is associated with the along-jet variation of meridional relative PV gradient (Waterman and Jayne 2011). Quantitatively, $\mathrm{BF}$ and BT contribute about $2 / 3$ and $1 / 3$ of the total EKE source, respectively. The generated EKE is either transported out of the domain by the divergent term $\mathrm{ADV}_{K}$ or dissipated through dissipation processes $D_{K}$. Wind work acts as an energy sink on the eddies and accounts for $\sim 18 \%$ of the total EKE dissipation.

The horizontal distribution of $\mathrm{BC}_{\text {temp }}$ bears some resemblance to that of BF (Figs. 5e,f), dominated by the positive values in the first crest of KE jet and negative centers near the trough. Besides along the KE jet, significant $\left(T^{1}\right)^{2}$ generation can also be found around the Oyashio Extension $(\mathrm{OE})$ front $\left(38^{\circ} \mathrm{N}, 143^{\circ} \mathrm{E}\right.$; Qiu et al. 2017). Integrating over the $\mathrm{KE}$, it is found that baroclinic conversion is the main source of $\left(T^{\sim 1}\right)^{2}$, of which around $60 \%$ is transferred to EKE and $35 \%$ is dissipated directly (Fig. 4). Air-sea heat exchange plays an important role in the budget and contributes to $36 \%$ of the total dissipation. Different from other energy production terms, generation of $\left(S^{\sim 1}\right)^{2}$ is confined to the Oyashio Extension region (Figs. $5 \mathrm{~g}, \mathrm{~h}$ ) and is mainly balanced by the dissipation. Freshwater flux is found to enhance $\left(S^{\sim 1}\right)^{2}$ but its magnitude is small. From Fig. 5 , it is evident that CESM successfully captures the spatial patterns of the four eddy energy production terms from ECCO2, confirming again the realism of the CESM simulation in simulating the eddy dynamics in the KE region.

As mentioned in section 2, both $\left(T^{\sim 1}\right)^{2}$ and $\left(S^{\sim 1}\right)^{2}$ are tightly related to EPE. It is important to understand whether temperature or salinity variability is more important in regulating the EPE. Based on Eq. (6), estimating the amplitudes of $\alpha T^{\sim 1}$ and $\beta S^{\sim 1}$ provides a direct way to measure their relative importance. Figures $6 \mathrm{a}$ and $6 \mathrm{~b}$ compare the horizontal distribution of depth-mean $\left|\alpha T^{\sim 1}\right|$ and $\left|\beta S^{\sim 1}\right|$ from CESM in the upper 350-m layer. Compared to $\left|\beta S^{\sim 1}\right|$, the amplitude of $\left|\alpha T^{\sim 1}\right|$ is about 3 times larger. As EPE is proportion to $\left(\rho^{\sim 1}\right)^{2}$, it can be concluded that $\mathrm{EPE}$ in the vicinity of KE is dominated by variability of temperature. Besides the comparison of magnitude, the relative importance of $\alpha T^{\sim 1}$ and $\beta S^{\sim 1}$ can also be understood in terms of budget analysis shown in Figs. $6 \mathrm{c}$ and $6 \mathrm{~d}$. The terms associated with $\alpha T^{\sim 1}$ $\left(\beta S^{\sim 1}\right)$ are obtained by multiplying Eqs. (2b) and (4) [Eqs. (2c) and (5)] by $\alpha^{2}\left(\beta^{2}\right)$. It is found that terms in Fig. $6 c$ are an order of magnitude larger than in Fig. 6d, indicating that EPE in the KE region is mainly regulated by the temperature variability. In addition, a comparison between $\alpha^{2} W_{\text {heat }}$ and $\beta^{2} W_{\text {water }}$ reveals that the air-sea heat exchange is much more important than the freshwater flux in influencing the EPE. Overall, the $T$-variance is much more important than the $S$-variance in the EPE/EKE budget and, as such, we mainly focus on the $T$-variance equation in the following.

\section{b. Air-sea interaction}

In this subsection, we explore the characteristics of the air-sea interaction terms and assess their role in eddy energy dissipation. As the role of freshwater flux is negligible (Figs. 4 and 6), we will mainly focus on $W_{\text {wind }}$ and $W_{\text {heat }}$ here. Figure 7 a shows the horizontal distribution of $W_{\text {heat }}$ derived from CESM. Oceanic eddies are found to release their potential energy to the overlying air in the domain (Ma et al. 2016), especially on the northern side of KE jet. According to observations (Sasaki and Minobe 2015), warm eddies are generally formed north of the mean path of the KE jet within $140^{\circ}-160^{\circ} \mathrm{E}$. Once pinched off, these eddies with higher SST and saturated surface specific humidity are exposed to much colder and drier atmosphere, which favors both latent and sensible heat exchange (Large and Yeager 2009). Moreover, the northwesterly wind during winter is stronger and drier on the northern side of KE jet, which intensifies this meridional difference as well. In addition to the heat exchange, momentum exchange between atmosphere and oceanic eddies is also prominent. Figure $7 \mathrm{~b}$ depicts the distribution of wind power input derived from CESM, in which $W_{\text {wind }}$ exhibits negative values along the $\mathrm{KE}$ jet. This indicates that wind forcing acts to spin down the oceanic eddies, consistent with previous studies (Renault et al. 2016a,b; Xu et al. 2016; Yang and Liang 2018). Negative centers are found along the $\mathrm{KE}$ jet within $145^{\circ}-142^{\circ} \mathrm{E}$, which are close to the shedding positions of strong eddies (Sasaki and Minobe 2015).

Interaction between atmosphere and oceanic eddies plays a marked role in regulating the eddy dissipation. A correlation analysis indicates that there is a significant linear relationship between surface energy flux $W_{\text {heat }}$ and oceanic energy dissipation $D_{\text {temp }}$, especially near the sea surface (not shown). To quantify the contribution of $W_{\text {heat }}$ to $D_{\text {temp }}$, we regress $D_{\text {temp }}$ at each depth onto $W_{\text {heat }} / h_{1}$. In the upper $20 \mathrm{~m}$, regression coefficient retains a value of greater than 0.5 , indicating that the air-sea heat exchange dominates the $T$-variance dissipation near the surface layer (Fig. 8a). The regression remains significant at $95 \%$ level up to $40 \mathrm{~m}$ based on the Student's $t$ test. Below $40 \mathrm{~m}$, the regression coefficient is small and can even become negative. Compared to the above, the role of wind power $W_{\text {wind }}$ in influencing EKE dissipation $D_{K}$ is relatively small (Fig. 8b). The positive 

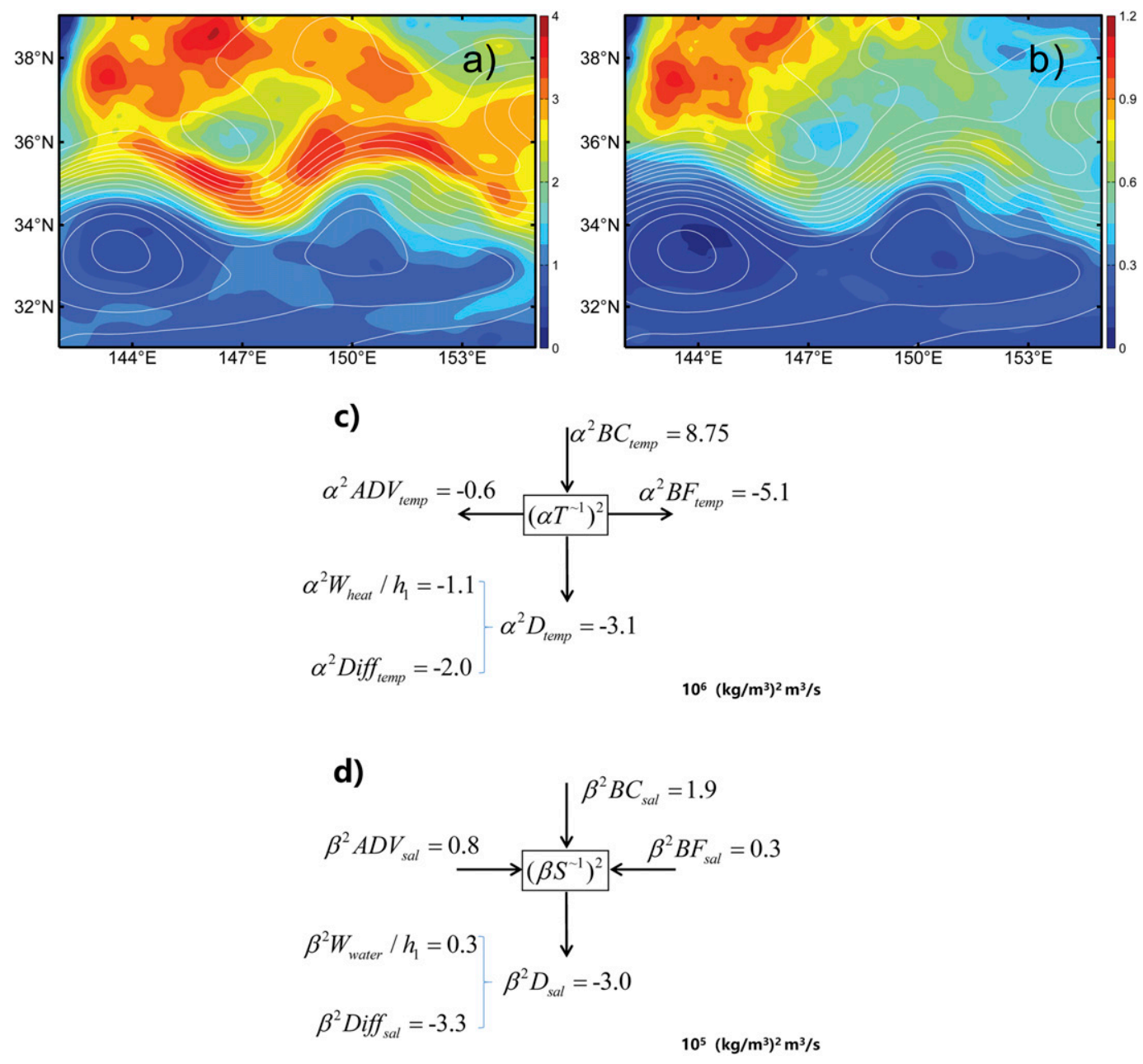

FIG. 6. Horizontal distribution of depth-mean (a) $\left|\alpha T^{1}\right|$ (color shading; $\mathrm{kg} \mathrm{m}^{-3}$ ) and (b) $\left|\beta S^{\sim 1}\right|$ (color shading; $\left.\mathrm{kg} \mathrm{m}^{-3}\right)$ in the upper $350 \mathrm{~m}$ derived from CESM, and eddy energy budget for (c) $\left(\alpha T^{\sim 1}\right)^{2}$ and (d) $\left(\beta S^{\sim 1}\right)^{2}$ in the upper $350-\mathrm{m} \mathrm{KE}$ region $\left(31^{\circ}-39^{\circ} \mathrm{N}, 142^{\circ}-155^{\circ} \mathrm{E}\right)$ derived from CESM.

regression coefficient between $W_{\text {wind }} / h_{1}$ and surface $D_{K}$ has a maximum value of 0.35 at the surface and decreases more rapidly in depth, becoming insignificant at around $40 \mathrm{~m}$. This indicates that the role of eddy wind power in regulating $D_{K}$ is secondary. Moreover, the ratio between the air-sea interaction term and the depth-integrated eddy energy dissipation from sea surface is also calculated. It is found that the contribution of $W_{\text {heat }}\left(W_{\text {wind }}\right)$ to depth-integrated $D_{\text {temp }}\left(D_{K}\right)$ decreases steadily as integration depth increases and approaches to a constant value of $0.36(0.18)$ at $120 \mathrm{~m}$ ( $75 \mathrm{~m}$; not shown), which gives an estimated maximal influence depth of $W_{\text {heat }}\left(W_{\text {wind }}\right)$.

In addition to the time-mean state, the seasonal variation of $W_{\text {heat }}$ and $W_{\text {wind }}$ is also examined. Figures 9a and $9 \mathrm{~b}$ show the horizontal distributions of $W_{\text {heat }}$ in winter (December, January, and February) and summer (June, July, and August). During winter, the large air-sea temperature and humidity difference and strong southeastward winds lead to a significant sensible and latent heat exchange between atmosphere and oceanic eddies. The pattern of $W_{\text {heat }}$ in winter bears some resemblance to that in Fig. 7a but its magnitude is much larger, suggesting that the annual-mean $W_{\text {heat }}$ is dominated by its winter component. Influenced by the reduced air-sea temperature difference and wind stress, the amplitude of $W_{\text {heat }}$ in summer is much smaller. Integrated over the KE region, $W_{\text {heat }}$ in winter is $-2.8 \times$ $10^{7} \mathrm{C}^{2} \mathrm{~m}^{3} \mathrm{~s}^{-1}$, which is about 3 times its value in summer $\left(-1.0 \times 10^{7}{ }^{\circ} \mathrm{C}^{2} \mathrm{~m}^{3} \mathrm{~s}^{-1}\right)$. The seasonal evolution of $W_{\text {heat }}$ leaves footprints on the vertical structure of dissipation. Figure 10a shows the vertical structures of $D_{\text {temp }}$ averaged over the KE region for winter and summer. In the presence of strong air-sea heat exchange, the turbulent dissipation term in winter is characterized by a surfaceintensified structure with considerably larger values 

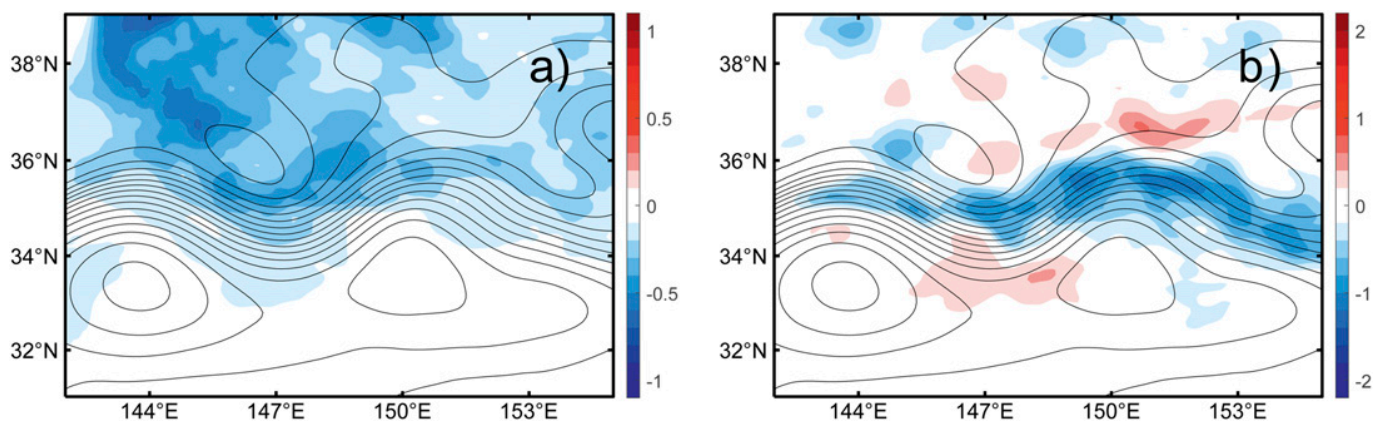

FIG. 7. Horizontal distribution of (a) $W_{\text {heat }}$ (color shading; $10^{-4}{ }^{\circ} \mathrm{C}^{2} \mathrm{~m} \mathrm{~s}^{-1}$ ) and (b) $W_{\text {wind }}$ (color shading; $10^{-2} \mathrm{~W} \mathrm{~m}^{-2}$ ) derived from CESM. Contours are mean SSH isolines.

near the sea surface than in summer. Moreover, a regression analysis suggests that the role of $W_{\text {heat }}$ in regulating $D_{\text {temp }}$ during winter is significant around $50 \mathrm{~m}$, which is deeper than in summer (not shown). Different from the winter vertical structure, the surface dissipation in summer becomes much smaller, consistent with the results in Fig. 8a. Similar to the heat exchange, eddy wind power in winter is also much stronger than that in summer, especially around the meandering $\mathrm{KE}$ jet (Figs. 9c,d). The total wind energy input values are estimated to be $-1.3 \times 10^{9}$ and $-0.6 \times 10^{9} \mathrm{~W}$ for winter and summer, respectively. Under its influence, $D_{K}$ in the upper 50-m layer is relatively larger in winter than in summer (Fig. 10b). As the wind power is not dominant in the EKE dissipation, the seasonal variation of $D_{K}$ is likely induced by the interior ocean processes.

The role of air-sea interaction is further investigated by comparing eddy energetics from CESM coupled and ocean-alone simulations. Compared to that from the coupled simulation, $W_{\text {heat }}$ in the ocean-alone run
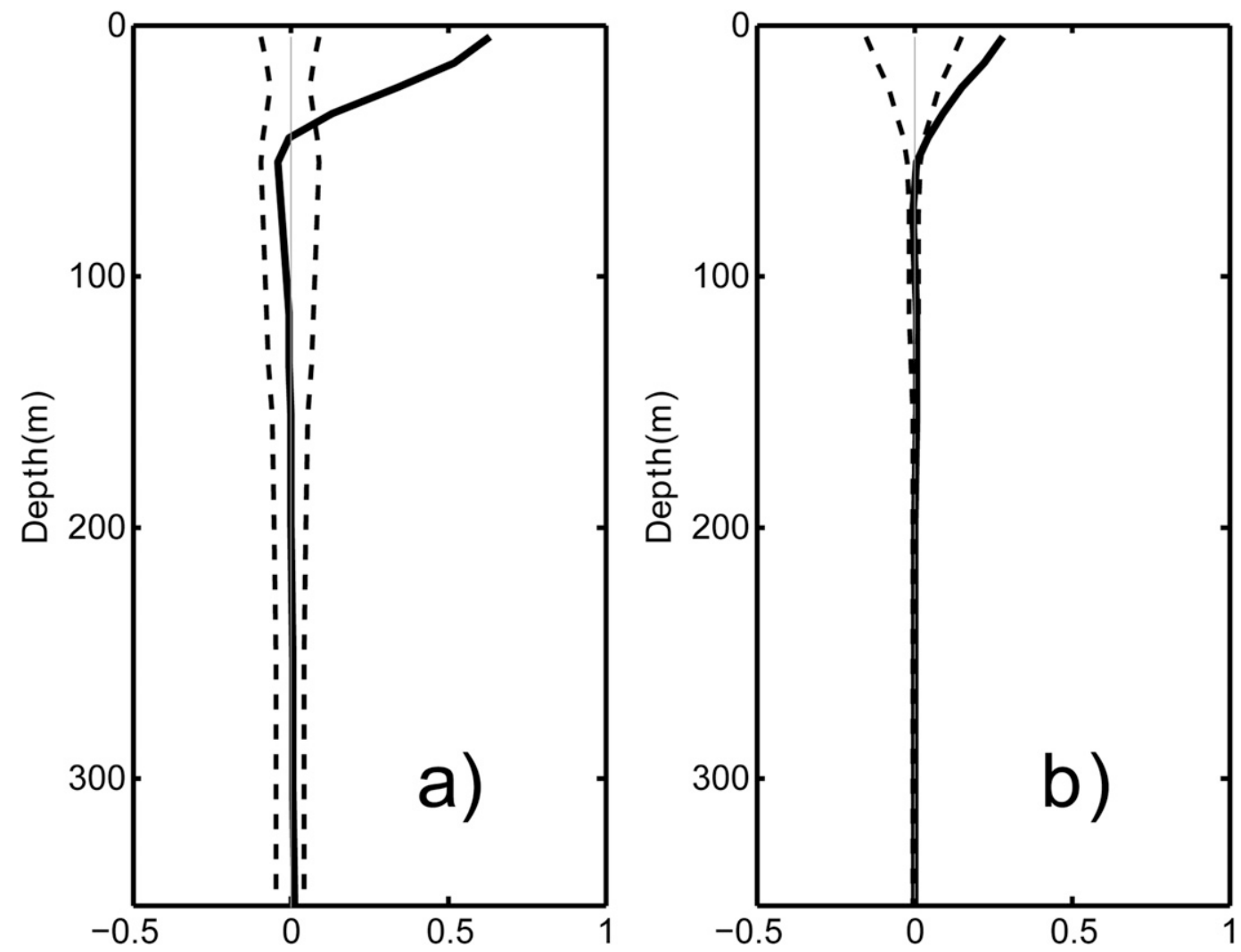

FIG. 8. Regression coefficient by (a) regressing the $D_{\text {temp }}$ upon $W_{\text {heat }} / h_{1}$ and (b) regressing the $D_{K}$ upon $W_{\text {wind }} / h_{1}$ within $31^{\circ}-39^{\circ} \mathrm{N}, 142^{\circ}-155^{\circ} \mathrm{E}$ at each depth layer based on CESM. Dashed lines indicate the rejection region at $95 \%$ confidence level based on the $t$ test. 

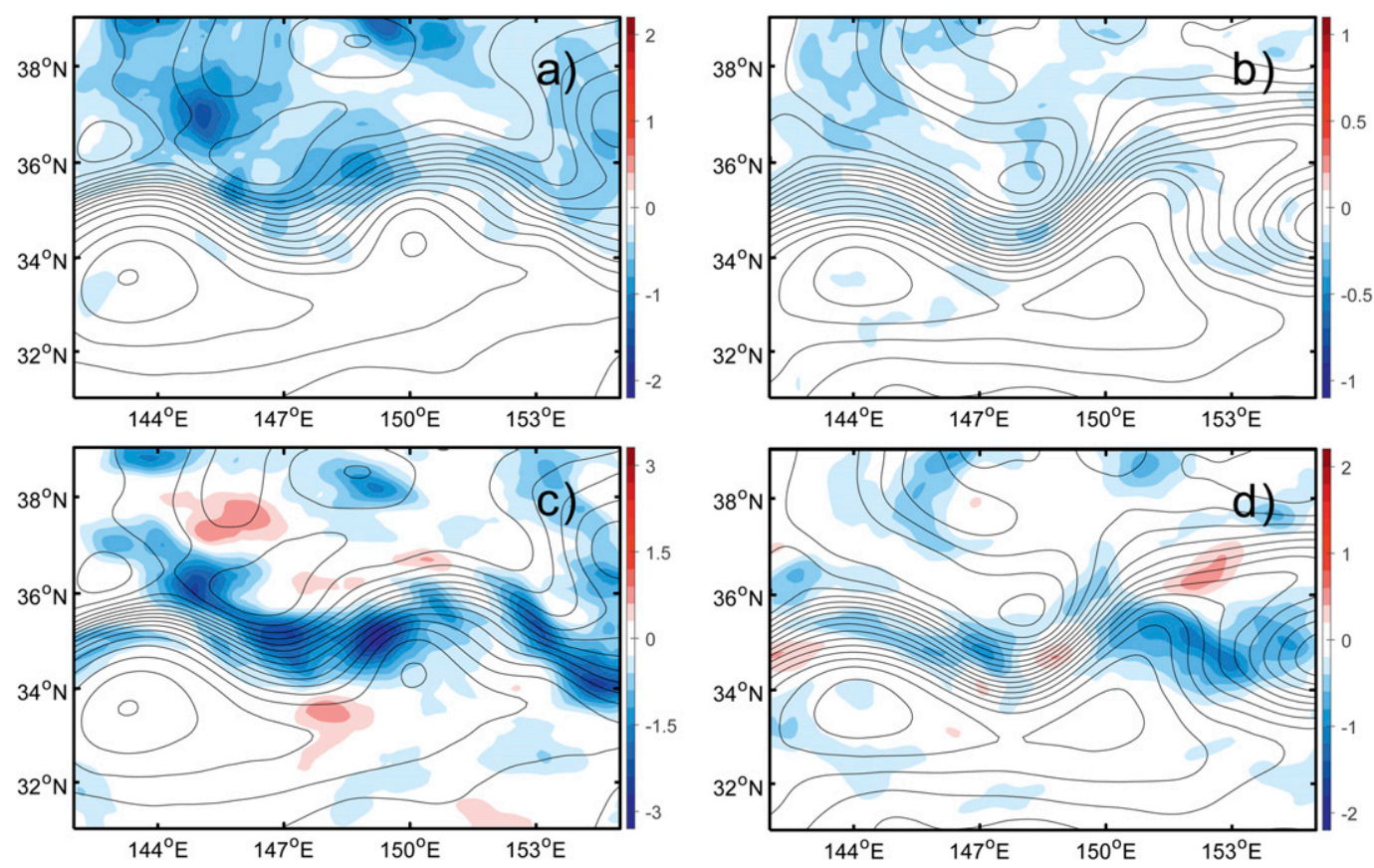

FIG. 9. Horizontal distribution of $W_{\text {heat }}$ for (a) winter and (b) summer (color shading; $10^{-4}{ }^{\circ} \mathrm{C}^{2} \mathrm{~m} \mathrm{~s}^{-1}$ ) derived from CESM. Contours are coinstantaneous mean SSH isolines. (c),(d) As in (a),(b), but for $W_{\text {wind }}$ (color shading; $10^{-2} \mathrm{~W} \mathrm{~m}^{-2}$ ).

shows a similar spatial pattern but with a significantly larger magnitude, indicative of an overestimation of airsea feedback effect on eddies (Fig. 11a). As mentioned earlier, CESM coupled run takes into the consideration of mesoscale eddy feedbacks with the atmosphere occurring in reality. In response to heat flux anomalies induced by the underlying eddies, the atmosphere adjusts its near-surface temperature and humidity profile. As a result, both the air-sea temperature and humidity differences are weakened, reducing the intensity of airsea feedback (Barsugli and Battisti 1998; P. Yang et al. 2018). However, since the atmosphere is fixed in the ocean-alone simulation and the atmospheric cannot respond to eddy-induced SST anomalies. As such, the surface heat exchange between mesoscale eddies and the overlying atmosphere is exaggerated, particularly on the northern side of the KE where eddy-induced turbulent heat fluxes are strong during winter when atmospheric synoptic storms are active (Ma et al. 2016). In addition to the thermodynamic feedback, surface wind stress is responsive to eddy currents. According to Renault et al. (2016a), the eddy current feedback partly compensates the negative eddy wind power. As this process is not included in the ocean-alone run, we expect that the eddy wind work will be overestimated (Fig. 11b).

A comparison between Figs. 7 and 11 reveals that the damping role of air-sea interaction is indeed overestimated in POP2. As a result, a larger proportion of eddy energy is dissipated through the air-sea boundary directly. This can be seen from the comparison of the vertical structures of energy dissipation terms (Fig. 12). In the case that the atmosphere is allowed to respond to eddy-induced SST, which acts to weaken the mesoscale air-sea feedback, both $D_{\text {temp }}$ and $D_{K}$ in the coupled simulation exhibit less surfaceintensified vertical distributions. In contrast, in the ocean-alone simulation more eddy energy is removed directly by atmosphere at the ocean surface, implying an erroneous representation of vertical mixing in dissipating eddy energy in ocean interior. Overall, these results support the notion that mesoscale air-sea interaction is essential to correctly simulate eddy energy dissipation in the ocean. When using ocean-alone models to simulate ocean eddies, the damping effect due to mesoscale air-sea interaction needs to be included as a parameterized process.

Our above discussion indicates that both $W_{\text {heat }}$ and $W_{\text {wind }}$ act as eddy killers by drawing energy from oceanic eddies. Besides their overall values within the mesoscale window, it is equally important to know the contributions of $W_{\text {heat }}$ and $W_{\text {wind }}$ from the highfrequency windows. Figure 13a shows the change of $W_{\text {heat }}$ as a function of periods varying from 4 days to 270 days. It is found that the atmosphere damps the ocean perturbations through heat exchange in both mesoscale and high-frequency windows. A comparison between 

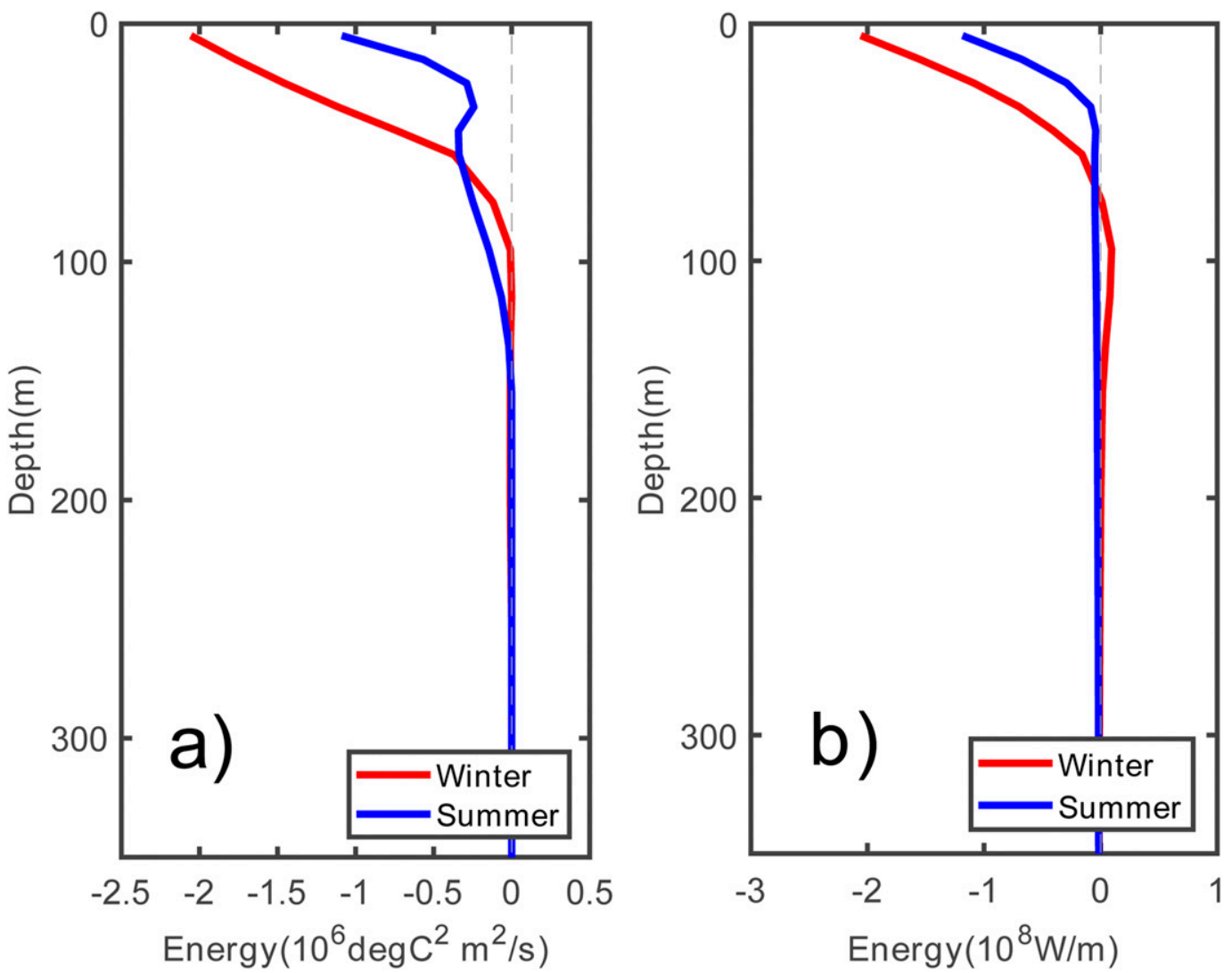

FIG. 10. Vertical distributions of (a) $D_{\text {temp }}$ and (b) $D_{K}$ in winter and summer integrated within the area $31^{\circ}-39^{\circ} \mathrm{N}$, $142^{\circ}-155^{\circ} \mathrm{E}$.

Figs. 13a and $13 \mathrm{~b}$ reveals that $W_{\text {heat }}$ is in proportion to the magnitude of the surface $T$-variance. This is not surprising as $Q_{\text {net }}^{\sim 1}$ is in direct proportion to $T^{\sim 1}$. Different from the heat exchange, $W_{\text {wind }}$ experiences a sign change from the high frequency to the mesoscale window (Fig. 13c) and implies a different role of air-sea interaction dynamics. Specifically, in the high-frequency band, atmospheric synoptic variability and storms directly influence surface Ekman flow and turbulence in the ocean, whereas the winds draw energy from oceanic eddies within the mesoscale window. Within the period bands between 34 and 270 days, the value of $W_{\text {wind }}$ is in proportion to the surface EKE, suggesting that stronger eddies have larger influence on the wind power input.

\section{Summary}

Based on the 4-yr daily mean output of a centurylong high-resolution CESM simulation, mesoscale airsea interaction and its role in eddy energetics in the
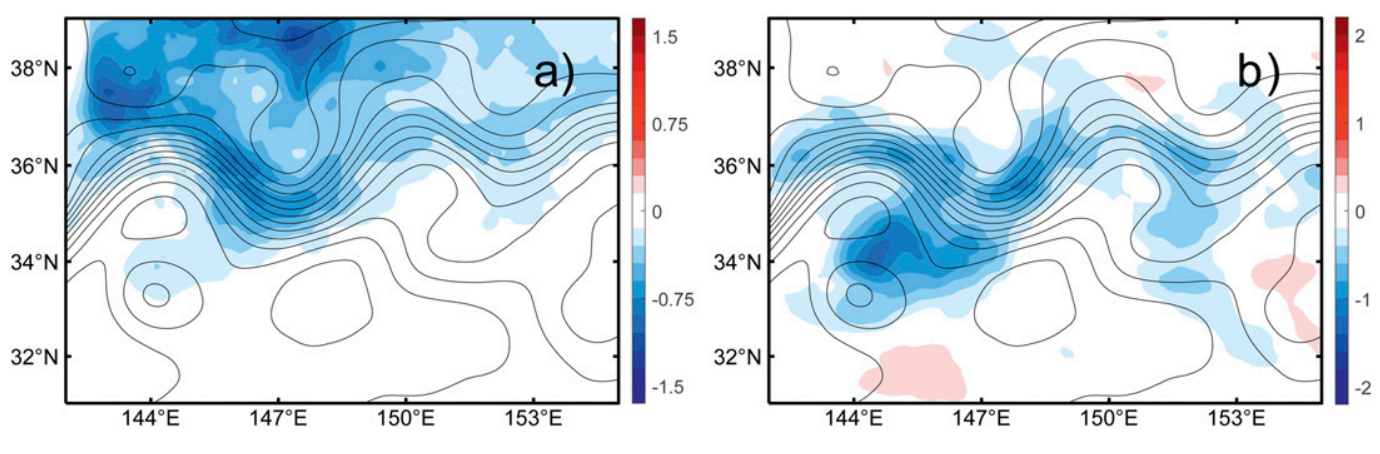

FIG. 11. As in Fig. 7, but based on ocean-alone model POP2. 

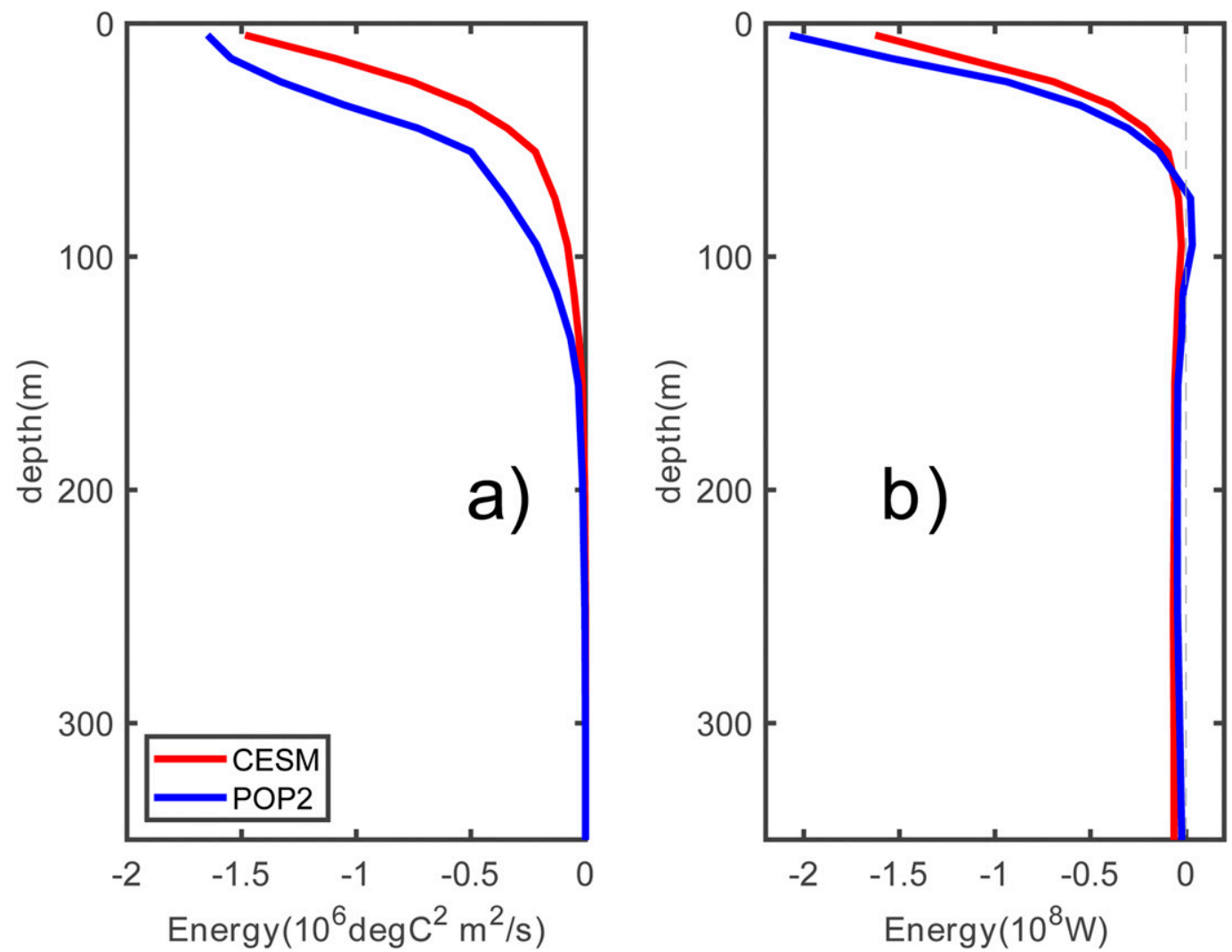

FIG. 12. Vertical distributions of (a) $D_{\text {temp }}$ and (b) $D_{K}$ integrated within the area $31^{\circ}-39^{\circ} \mathrm{N}, 142^{\circ}-155^{\circ} \mathrm{E}$ derived from CESM and POP2, respectively.

Kuroshio Extension region are explored in this study. The major results of this study are summarized as follows:

1) The baroclinic pathway associated with temperature variability is found to be the main eddy energy source in the KE region. In the upper 350-m-layer energy
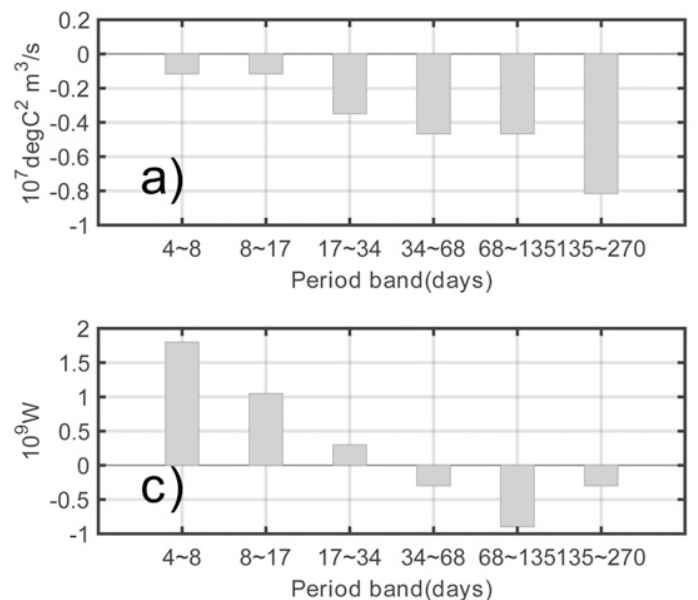

balance, the heat exchange between atmosphere and oceanic eddies $\left(W_{\text {heat }}\right)$ accounts for $36 \%$ of the $T$-variance dissipation, while only $18 \%$ of EKE dissipation can be attributed to wind power ( $\left.W_{\text {wind }}\right)$. In comparison, the role of the freshwater flux ( $\left.W_{\text {water }}\right)$ in $S$-variance dissipation is negligible.
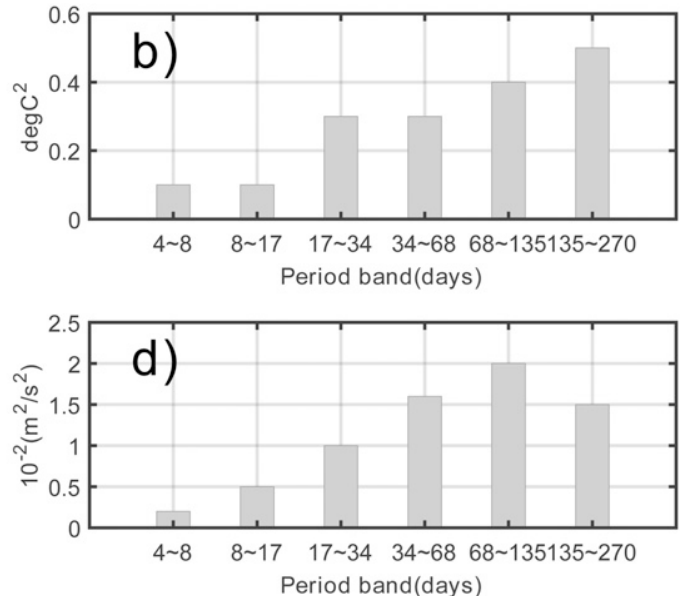

FIG. 13. Change of (a) $W_{\text {heat }}$, (b) surface $\left(T^{1}\right)^{2}$, (c) $W_{\text {wind }}$, and (d) surface $\left(u^{\sim 1}\right)^{2}+\left(v^{\sim 1}\right)^{2}$ vs period. All the variables are integrated in the area $31^{\circ}-39^{\circ} \mathrm{N}, 142^{\circ}-155^{\circ} \mathrm{E}$. 
2) $W_{\text {heat }}$ dominates the $T$-variance dissipation in the upper 35-m layer, whereas the role of $W_{\text {wind }}$ in regulating the EKE dissipation is secondary. Both $W_{\text {heat }}$ and $W_{\text {wind }}$ are much larger in winter than in summer.

3) Distinct from the coupled CESM model, the oceanalone simulation overestimates the damping role of $W_{\text {heat }}$ and $W_{\text {wind. }}$. As a result, the vertical structure of eddy energy dissipation is characterized with an enhanced surface-intensified profile. It hints that the inclusion of mesoscale air-sea interaction is essential to correctly simulate eddy energy dissipation in the ocean.

4) Within both the high frequency and mesoscale windows, $W_{\text {heat }}$ acts as an eddy killer and its value is in proportion to the surface $T$-variance. In contrast, $W_{\text {wind }}$ is found to draw energy from the ocean at eddy time scales, but drive the high-frequency processes in the ocean.

This study has explored the characteristics of airsea interaction in the $\mathrm{KE}$ region and emphasized its importance in the eddy energy dissipation. It should be noted that statistical studies based on eddytracking scheme (Chelton et al. 2011) are required to further clarify the detailed processes as to how airsea interaction influences the eddy evolution. The imprint of air-sea interaction on energy cascade among the three time-scale windows is not fully analyzed in the present study. Furthermore, by influencing the eddy energy dissipation, the air-sea heat exchange may further regulate the interior ocean processes such as buoyancy forcing (Ma et al. 2016) and vertical eddy energy fluxes, especially during the strong storm events in winter. How the air-sea interaction modulates these processes needs to be investigated in future studies.

Acknowledgments. This research is supported by the National Natural Science Foundation for Young Scientists of China (41806008), National Key Research and Development Program of China (2016YFC1402606), National Natural Science Foundation of China (41490644, U1406401, 41622602, U1606402), Shandong Provincial Natural Science Foundation (ZR2019BD015), Pilot National Laboratory for Marine Science and Technology (Qingdao) (2017ASTCPES05 and 2017ASKJ01). HY is partially supported by the Chinese Scholarship Council, and ZC is partially supported by the 'Taishan' Talents program and Fundamental Research Funds for the Central Universities (201762013). PC acknowledges the support from the National Science Foundation Grant AGS-1462127. We thank Frank O. Bryan and R. Justin Small for their invaluable comments on this work. The CESM project is supported by the National Science Foundation and the Office of Science (BER) of the U.S. Department of Energy. Computing resources for the CESM coupled case were provided by the Climate Simulation Laboratory at NCAR's Computational and Information Systems Laboratory (CISL), as well as by the Texas Advanced Computing Center at The University of Texas at Austin and the Texas A\&M Supercomputing Facility, sponsored by the National Science Foundation and other agencies. Computing resources for POP2 were provided by Center for High Performance Computing and System Simulation, Pilot National Laboratory for Marine Science and Technology (Qingdao, China). The original CESM code can be obtained through the URL http://www.cesm.ucar.edu/models/current.html. The ECCO2 product can be obtained through the URL http://apdrc.soest.hawaii.edu/data/. This is a collaborative project between the Ocean University of China (OUC), Texas A\&M University (TAMU) and the National Center for Atmospheric Research (NCAR) and completed through the International Laboratory for High Resolution Earth System Prediction (iHESP) - a collaboration by the Qingdao National Laboratory for Marine Science and Technology Development Center, Texas A\&M University, and the National Center for Atmospheric Research. Comments from the anonymous reviewers are also greatly appreciated.

\section{APPENDIX A}

\section{Eddy Energy Equations}

The Navier-Stokes equations under the hydrostatic and Boussinesq approximations are

$$
\begin{aligned}
\frac{\partial u}{\partial t}+\nabla \cdot(u \mathbf{v})-f v & =-\frac{1}{\rho_{0}} \frac{\partial p}{\partial x}+A_{M} \nabla^{2} u+\frac{\partial}{\partial z} \mu \frac{\partial u}{\partial z} \\
\frac{\partial v}{\partial t}+\nabla \cdot(v \mathbf{v})+f u & =-\frac{1}{\rho_{0}} \frac{\partial p}{\partial y}+A_{M} \nabla^{2} v+\frac{\partial}{\partial z} \mu \frac{\partial v}{\partial z} \\
\nabla \cdot \mathbf{v} & =0 \\
\frac{\partial p}{\partial z} & =-\rho g \\
\frac{\partial T^{*}}{\partial t}+\nabla \cdot\left(\mathbf{v} T^{*}\right) & =A_{H} \nabla^{2} T^{*}+\frac{\partial}{\partial z} \kappa \frac{\partial T^{*}}{\partial z}+F_{T} \\
\frac{\partial S^{*}}{\partial t}+\nabla \cdot\left(\mathbf{v} S^{*}\right) & =A_{H} \nabla^{2} S^{*}+\frac{\partial}{\partial z} \kappa \frac{\partial S^{*}}{\partial z}+F_{S}
\end{aligned}
$$

Here, $T^{*}$ and $S^{*}$ present potential temperature and salinity, respectively. In the CESM model, the air-sea interaction terms are involved via the sea surface boundary $(z=0)$ conditions (Smith et al. 2010): 

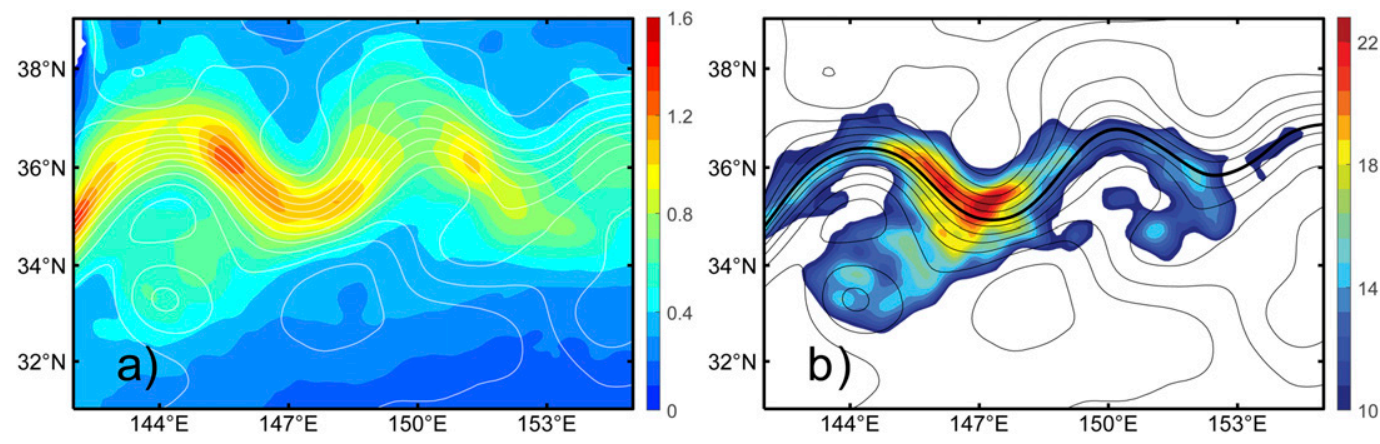

FIG. B1. (a) Mean velocity field (color shading; $\mathrm{m} \mathrm{s}^{-1}$ ) and (b) time-mean surface EKE field (color shading; $0.01 \mathrm{~m}^{2} \mathrm{~s}^{-2}$ ) based on POP2. Contours denote mean SSH field.

$$
\begin{aligned}
& \mu \frac{\partial \mathbf{u}}{\partial z}=\frac{\tau}{\rho_{0}}, \\
& \kappa \frac{\partial T}{\partial z}=\frac{Q_{\text {net }}}{c_{p} \rho_{0}}, \\
& \kappa \frac{\partial S}{\partial z}=\frac{1}{\rho_{0}}[-(E-P) \cdot \mathrm{SSS}] .
\end{aligned}
$$

By taking the mesoscale component of Eq. (A4) and multiplying it by $w^{\sim 1}$, we get

$$
\frac{\partial p^{\sim 1}}{\partial z} w^{\sim 1}=-\rho^{\sim 1} w^{\sim 1} g
$$

Using the mesoscale component of Eq. (A3) and combining it with Eq. (A10), we have

$$
\frac{\partial\left(p^{\sim 1} w^{\sim 1}\right)}{\partial z}+p^{\sim 1}\left(\frac{\partial u^{\sim 1}}{\partial x}+\frac{\partial v^{\sim 1}}{\partial x}\right)=-\rho^{\sim 1} w^{\sim 1} g .
$$

Multiplying the mesoscale component of Eqs. (A1) and (A2) by $\rho_{0} u^{\sim 1}$ and $\rho_{0} v^{\sim 1}$, respectively, summing them, and substituting into Eq. (A11) we obtain Eq. (2a).

To obtain the $T$-variance equation, we first decompose $T^{*}$ as

$$
T^{*}=\bar{T}(z)+T,
$$

where $\bar{T}(z)$ denotes the potential temperature averaged over the $z$-plane and time. Substituting Eqs. (A3) and (A12) into Eq. (A5), we obtain

$$
\begin{aligned}
\frac{\partial T}{\partial t}+\nabla \cdot(\mathbf{v} T)+w \frac{\partial \bar{T}(z)}{\partial z}= & A_{H} \nabla^{2} T+\frac{\partial}{\partial z} \kappa \frac{\partial[T+\bar{T}(z)]}{\partial z} \\
& +F_{T} .
\end{aligned}
$$

By taking the mesoscale component of Eq. (A13) and multiplying by $T^{\sim 1}$, we have Eq. (2b) in the mesoscale window. The $S$-variance equation can be derived through the same procedures. Because the local vertical mixing terms for temperature and salinity are not available in the CESM and POP2 output, we treat energy dissipation terms as residuals of the equations here. As CESM provides the tendency, nonlinear advection, the horizontal mixing terms, and $F_{T} / F_{S}$ in Eqs. (A5) and (A6), we believe that the calculated residual terms are accurate.

In the surface layer, $(\partial / \partial z) \mu(\partial \mathbf{u} / \partial z)$ associated with wind stress is approximate to constant and surface wind stress is zero at the bottom of this layer. Therefor the friction due to wind forcing in the surface layer can be represented by $\tau / \rho_{0} h_{1}$. Multiplying its mesoscale component by $\left(\rho_{0} u^{\sim 1}\right.$, $\rho_{0} v^{\sim 1}$ ) we get $W_{\text {wind }}$ in Eq. (3). Using the same method and assumption, we can get $W_{\text {heat }}$ and $W_{\text {water }}$ in Eqs. (4) and (5).

According to Liang and Robinson (2005) and Yang and Liang (2016), the energy terms BT, $\mathrm{BC}_{\text {temp }}$, and $\mathrm{BC}_{\mathrm{sal}}$ represent window-window interactions associated with the mesoscale variability. They can be decomposed into 1) energy exchange between the mean flow and eddy, 2) energy exchange between high-frequency processes and eddies, 3) mean flow-high frequency interaction in the mesoscale window, and 4) eddy-eddy interaction. We have respectively calculated these four components and found that the eddy-mean flow interaction (the first process above) dominates $\mathrm{BT}, \mathrm{BC}_{\text {temp }}$, and $\mathrm{BC}_{\text {sal }}$. Therefore, we treat these three terms as resulting from the eddy-mean flow interaction in this study. Different from them, other terms in Eqs. (2a)-(2c) describe the energy transfer within the mesoscale window.

\section{APPENDIX B}

\section{Mean and Eddy Fields Simulated by POP2}

Figure B1a shows the mean velocity field in the KE region simulated by POP2. After separating from the Japan coast around $35^{\circ} \mathrm{N}$, the mean path of the $\mathrm{KE}$ is 
characterized by the presence of two quasi-stationary meanders with the ridges located near $144^{\circ}$ and $150^{\circ} \mathrm{E}$, respectively. The maximum velocity reaches $1.5 \mathrm{~m} \mathrm{~s}^{-1}$, which is close to that derived from CESM (Fig. 1). Moreover, the pattern of EKE derived from POP2 depicts large values in the vicinity of KE jet with the largest amplitude located between the quasi-stationary meanders (Fig. B1b), resembling that from the coupled model as well (Fig. 3a). Overall, comparison between the two cases reveals that the background circulation does not change much under different forcing fields. Therefore, we can compare the eddy energetics based on these two outputs.

\section{REFERENCES}

Barsugli, J., and D. Battisti, 1998: The basic effects of atmosphereocean thermal coupling on midlatitude variability. J. Atmos Sci., 55, 477-493, https://doi.org/10.1175/1520-0469(1998)055<0477: TBEOAO $>2.0 . \mathrm{CO} ; 2$.

Berloff, P., and J. McWilliams, 1999: Large-scale, low-frequency variability in wind-driven ocean gyres. J. Phys. Oceanogr., 29, 1925-1945, https://doi.org/10.1175/1520-0485(1999)029<1925: LSLFVI $>2.0 . \mathrm{CO} ; 2$.

Bishop, S., 2013: Divergent eddy heat fluxes in the Kuroshio Extension at $144^{\circ}-148^{\circ}$ E. Part II: Spatiotemporal variability. J. Phys. Oceanogr., 43, 2416-2431, https://doi.org/10.1175/ JPO-D-13-061.1.

_- F. Bryan, and R. Small, 2015: Bjerknes-like compensation in the wintertime North Pacific. J. Phys. Oceanogr., 45, 1339 1355, https://doi.org/10.1175/JPO-D-14-0157.1.

—, R. J. Small, F. O. Bryan, and R. A. Tomas, 2017: Scale dependence of midlatitude air-sea interaction. J. Climate, $\mathbf{3 0}$ 8207-8221, https://doi.org/10.1175/JCLI-D-17-0159.1.

Booth, J., L. Thompson, J. Patoux, K. Kelly, and S. Dickinson, 2010: The signature of the midlatitude tropospheric storm tracks in the surface winds. J. Climate, 23, 1160-1174, https:// doi.org/10.1175/2009JCLI3064.1.

Chelton, D., M. Schlax, M. Freilich, and R. Milliff, 2004: Satellite measurements reveal persistent small-scale features in ocean winds. Science, 303, 978-983, https://doi.org/10.1126/ science.1091901.

, - — , and R. Samelson, 2011: Global observations of nonlinear mesoscale eddies. Prog. Oceanogr., 91, 167-216, https:// doi.org/10.1016/j.pocean.2011.01.002.

Chen, R., G. Flierl, and C. Wunsch, 2014: A description of local and nonlocal eddy-mean flow interaction in a global eddy-permitting state estimate. J. Phys. Oceanogr., 44, 2336-2352, https://doi.org/ 10.1175/JPO-D-14-0009.1.

Cornillon, P., and K.-A. Park, 2001: Warm core ring velocities inferred from NSCAT. Geophys. Res. Lett., 28, 575-578, https:// doi.org/10.1029/2000GL011487.

Eden, C., and H. Dietze, 2009: Effects of mesoscale eddy/wind interactions on biological new production and eddy kinetic energy. J. Geophys. Res., 114, C05023, https://doi.org/10.1029/ 2008JC005129.

Gan, B., and L. Wu, 2015: Feedbacks of sea surface temperature to wintertime storm tracks in the North Atlantic. J. Climate, 28 , 306-323, https://doi.org/10.1175/JCLI-D-13-00719.1.

Gaube, P., D. Chelton, R. Samelson, M. Schlax, and L. O’Neill, 2015: Satellite observations of mesoscale eddy-induced
Ekman pumping. J. Phys. Oceanogr., 45, 104-132, https:// doi.org/10.1175/JPO-D-14-0032.1.

Itoh, S., and I. Yasuda, 2010: Characteristics of mesoscale eddies in the Kuroshio-Oyashio Extension region detected from the distribution of the sea surface height anomaly. J. Phys. Oceanogr., 40, 1018-1034, https://doi.org/10.1175/2009JPO4265.1.

Joyce, T., I. Yasuda, Y. Hiroe, K. Komatsu, K. Kawasaki, and F. Bahr, 2001: Mixing in the meandering Kuroshio Extension and the formation of North Pacific Intermediate Water. J. Geophys. Res., 106, 4397-4404, https://doi.org/ 10.1029/2000JC000232.

Kelly, K., S. Dickinson, M. McPhaden, and G. Johnson, 2001: Ocean currents evident in satellite wind data. Geophys. Res. Lett., 28, 2469-2472, https://doi.org/10.1029/2000GL012610.

_ , R. Small, R. Samelson, B. Qiu, T. Joyce, Y. Kwon, and M. Cronin, 2010: Western boundary currents and frontal air-sea interaction: Gulf Stream and Kuroshio Extension. J. Climate, 23, 5644-5667, https://doi.org/10.1175/2010JCLI3346.1.

Kida, S., and Coauthors, 2015: Oceanic fronts and jets around Japan: A review. J. Oceanogr., 71, 469-497, https://doi.org/ 10.1007/s10872-015-0283-7.

Konda, M., H. Ichikawa, H. Tomita, and M. Cronin, 2010: Surface heat flux variations across the Kuroshio Extension as observed by surface flux buoys. J. Climate, 23, 5206-5221, https:// doi.org/10.1175/2010JCLI3391.1.

Large, W., and S. Yeager, 2004: Diurnal to decadal global forcing for ocean and sea-ice models: The data sets and flux climatologies. NCAR Tech. Note NCAR/TN-460+STR, 111 pp., https://doi.org/10.5065/D6KK98Q6.

— and — 2009: The global climatology of an interannually varying air-sea flux data set. Climate Dyn., 33, 341-364, https:// doi.org/10.1007/s00382-008-0441-3.

_ ing-A review and a model with a nonlocal boundary layer parameterization. Rev. Geophys., 32, 363-403, https://doi.org/ 10.1029/94RG01872.

Liang, X. S., 2016: Canonical transfer and multiscale energetics for primitive and quasigeostrophic atmospheres. J. Atmos. Sci., 73, 4439-4468, https://doi.org/10.1175/JAS-D-16-0131.1.

— , and A. Robinson, 2005: Localized multiscale energy and vorticity analysis: I. Fundamentals. Dyn. Atmos. Oceans, 38, 195-230, https://doi.org/10.1016/j.dynatmoce.2004.12.004.

Lorenz, E., 1955: Available potential energy and the maintenance of the general circulation. Tellus, 7, 157-167, https://doi.org/ 10.3402/tellusa.v7i2.8796.

Ma, X., and Coauthors, 2016: Western boundary currents regulated by interaction between ocean eddies and the atmosphere. Nature, 535, 533-537, https://doi.org/10.1038/nature18640.

Marshall, J., A. Adcroft, C. Hill, L. Perelman, and C. Heisey, 1997: A finite-volume, incompressible Navier Stokes model for studies of the ocean on parallel computers. J. Geophys. Res., 102, 5753-5766, https://doi.org/10.1029/96JC02775.

Menemenlis, D., I. Fukumori, and T. Lee, 2005: Using Green's functions to calibrate an ocean general circulation model. Mon. Wea. Rev., 133, 1224-1240, https://doi.org/10.1175/ MWR2912.1.

Nakamura, H., T. Sampe, Y. Tanimoto, and A. Shimpo, 2004: Observed associations among storm tracks, jet streams and midlatitude oceanic fronts. Earth's Climate: The OceanAtmosphere Interaction, Geophys. Monogr., Vol. 147, Amer. Geophys. Union, 329-346.

Nakano, H., H. Tsujino, and K. Sakamoto, 2013: Tracer transport in cold-core rings pinched off from the Kuroshio Extension in an 
eddy-resolving ocean general circulation model. J. Geophys. Res. Oceans, 118, 5461-5488, https://doi.org/10.1002/JGRC.20375.

Qiu, B., and S. Chen, 2005: Variability of the Kuroshio Extension jet, recirculation gyre, and mesoscale eddies on decadal time scales. J. Phys. Oceanogr., 35, 2090-2103, https://doi.org/10.1175/JPO2807.1.

— , and — 2010: Eddy-mean flow interaction in the decadally modulating Kuroshio Extension system. Deep-Sea Res. II, 57, 1098-1110, https://doi.org/10.1016/j.dsr2.2008.11.036.

— - and _ 2011: Effect of decadal Kuroshio Extension jet and eddy variability on the modification of North Pacific Intermediate Water. J. Phys. Oceanogr., 41, 503-515, https:// doi.org/10.1175/2010JPO4575.1.

_ K. Kelly, and T. Joyce, 1991: Mean flow and variability in the Kuroshio Extension from Geosat altimetry data. J. Geophys. Res., 96, 18 491-18 507, https://doi.org/10.1029/91JC01834.

$\longrightarrow$, S. Chen, N. Schneider, and B. Taguchi, 2014: A coupled decadal prediction of the dynamic state of the Kuroshio Extension system. J. Climate, 27, 1751-1764, https://doi.org/10.1175/ JCLI-D-13-00318.1.

,-- , and,- 2017 : Dynamical links between the decadal variability of the Oyashio and Kuroshio Extensions. J. Climate, 30, 9591-9605, https://doi.org/10.1175/JCLI-D-17-0397.1.

Renault, L., M. Molemaker, J. McWilliams, A. Shchepetkin, F. Lemarié, D. Chelton, S. Illig, and A. Hall, 2016a: Modulation of wind work by oceanic current interaction with the atmosphere. J. Phys. Oceanogr., 46, 1685-1704, https://doi.org/ 10.1175/JPO-D-15-0232.1.

— — _ J. Gula, S. Masson, and J. McWilliams, 2016b: Control and stabilization of the Gulf Stream by oceanic current interaction with the atmosphere. J. Climate, 46, 3439-3453, https://doi.org/10.1175/JPO-D-16-0115.1.

_ J. McWilliams, and S. Masson, 2017: Satellite observations of imprint of oceanic current on wind stress by air-sea coupling. Sci. Rep., 7, 17747, https://doi.org/10.1038/s41598-017-17939-1.

Sampe, T., and S.-P. Xie, 2007: Mapping high sea winds from space: A global climatology. Bull. Amer. Meteor. Soc., 88, 1965-1978, https://doi.org/10.1175/BAMS-88-12-1965.

Sasaki, Y., and S. Minobe, 2015: Climatological mean features and interannual to decadal variability of ring formations in the Kuroshio Extension region. J. Oceanogr., 71, 499-509, https:// doi.org/10.1007/s10872-014-0270-4.

Seo, H., A. Miller, and J. Norris, 2016: Eddy-wind interaction in the California Current System: Dynamics and impacts. J. Phys. Oceanogr., 46, 439-459, https://doi.org/10.1175/JPO-D-15-0086.1.

Small, R., J. Bacmeister, D. Bailey, A. Baker, S. Bishop, F. Bryan, and Coauthors, 2014: A new synoptic scale resolving global climate simulation using the Community Earth System Model.
J. Adv. Model. Earth Syst., 6, 1065-1094, https://doi.org/ 10.1002/2014MS000363.

Smith, R., and Coauthors, 2010: The Parallel Ocean Program (POP) reference manual: Ocean component of the Community Climate System Model (CCSM). Tech. Rep. LAUR?10? 01853, Los Alamos National Laboratory, 141 pp.

Taguchi, B., S. Xie, N. Schneider, M. Nonaka, H. Sasaki, and Y. Sasai, 2007: Decadal variability of the Kuroshio Extension: Observations and an eddy-resolving model hindcast. J. Climate, 20, 2357-2377, https://doi.org/10.1175/JCLI4142.1.

von Storch, J., C. Eden, I. Fast, H. Haak, D. Hernández-Deckers, E. Maier-Reimer, J. Marotzke, and D. Stammer, 2012: An estimate of the Lorenz energy cycle for the world ocean based on the 1/108 STORM/NCEP simulation. J. Phys. Oceanogr., 42, 2185-2205, https://doi.org/10.1175/JPO-D-12079.1.

Waterman, S., and S. Jayne, 2011: Eddy-mean flow interaction in the along-stream development of a western boundary current jet: An idealized model study. J. Phys. Oceanogr., 41, 682-707, https://doi.org/10.1175/2010JPO4477.1.

Wunsch, C., and Coauthors, 2009: The global general circulation of the ocean estimated by the ECCO-Consortium. Oceanogr., 22, 88-103, https://doi.org/10.5670/oceanog.2009.41.

Xu, C., X. Zhai, and X. Shang, 2016: Work done by atmospheric winds on mesoscale ocean eddies. Geophys. Res. Lett., 43, 12174-12 180, https://doi.org/10.1002/2016GL071275.

Yang, H., B. Qiu, P. Chang, L. Wu, S. Wang, Z. Chen, and Y. Yang, 2018: Decadal variability of eddy characteristics and energetics in the Kuroshio Extension: Unstable versus stable states. J. Geophys. Res., 123, 6653-6669, https://doi.org/ 10.1029/2018JC014081.

Yang, P., Z. Jing, and L. Wu, 2018: An assessment of representation of oceanic mesoscale eddy-atmosphere interaction in the current generation of general circulation models and reanalyses. Geophys. Res. Lett., 45, 11 856-11 865, https:// doi.org/10.1029/2018GL080678.

Yang, Y., and X. S. Liang, 2016: The instabilities and multiscale energetics underlying the mean-interannual-eddy interactions in the Kuroshio Extension region. J. Phys. Oceanogr., 46, 14771494, https://doi.org/10.1175/JPO-D-15-0226.1.

$\longrightarrow$, and - 2018: On the seasonal eddy variability in the Kuroshio Extension. J. Phys. Oceanogr., 48, 1675-1689, https://doi.org/ 10.1175/JPO-D-18-0058.1.

,-- B. Biu, and S. Chen, 2017: On the decadal variability of the eddy kinetic energy in the Kuroshio Extension. J. Phys. Oceanogr., 47, 1169-1187, https://doi.org/10.1175/JPO-D-160201.1. 